\title{
Les règlements des conflits de succession dans la noblesse bretonne au XIII ${ }^{\mathrm{e}}$ siècle
}

\section{Frédéric Morvan}

\section{(2) OpenEdition Journals}

\section{Édition électronique}

URL : http://journals.openedition.org/abpo/162

DOI : $10.4000 / a b p o .162$

ISBN : 978-2-7535-1514-7

ISSN : 2108-6443

Éditeur

Presses universitaires de Rennes

Édition imprimée

Date de publication : 30 juin 2009

Pagination : 7-53

ISBN : 978-2-7535-0941-2

ISSN : 0399-0826

\section{Référence électronique}

Frédéric Morvan, «Les règlements des conflits de succession dans la noblesse bretonne au XIII siècle », Annales de Bretagne et des Pays de l'Ouest [En ligne], 116-2 | 2009, mis en ligne le 30 juin 2011, consulté le 01 mai 2019. URL : http://journals.openedition.org/abpo/162 ; DOI : 10.4000/abpo.162 


\title{
Les règlements des conflits de succession dans la noblesse bretonne au XIII ${ }^{\mathrm{e}}$ siècle
}

\author{
Frédéric MORvan \\ agrégé d'histoire, docteur en histoire médiévale
}

Analyser les règlements des conflits de succession de la noblesse bretonne au XIII ${ }^{e}$ siècle est particulièrement intéressant car cela équivaut à appréhender l'histoire d'une autre manière, à avoir un regard différent sur les événements et sur les gens de cette époque. Les successions dans la noblesse bretonne ont été nombreuses pendant cette période ${ }^{1}$. Mais avant de commencer, il est possible de se poser plusieurs questions : qu'est-ce que la noblesse bretonne au XIII siècle? Quels sont les grands traits du $\mathrm{XIII}^{\mathrm{e}}$ siècle breton? Et enfin, quels furent les critères qui réglementaient au début du XIII ${ }^{\mathrm{e}}$ siècle les successions de cette noblesse?

Définir la noblesse bretonne au XIII ${ }^{e}$ siècle est quelque chose de périlleux. Bien sûr, au sens strict, un noble est quelqu'un qui est connu et reconnu de ses contemporains. Il se trouve au sommet de la société détenant pouvoir politique, économique et social, voire religieux. Toutefois, les choses se compliquent lorsqu'on entre dans les détails. Pour résumer, selon Paul Guilhermoz ${ }^{2}$, historien du droit, tout noble, avant le XIII siècle, était un combattant quelle que fût l'ancienneté ou la réputation de sa famille. Le métier l'emportait encore sur le sang. Ce même historien considérait que la genèse du statut nobiliaire n'était intervenue qu'au XIII ${ }^{\mathrm{e}}$ siècle, c'est-àdire dans notre période d'étude. Une trentaine d'années plus tard, Marc Bloch, dans La société féodale, reprit ce postulat à son compte et écrivit que la noblesse «n'a commencé à se constituer véritablement que vers la fin du XIII' siècle; le siècle suivant a vu s'en fixer les contours ". C'est alors seulement que la " noblesse de fait devient " la noblesse de droit ", " que la chevalerie se transforme en caste héréditaire ». Pour la période précédente,

1. Pour la période postérieure, voir HalgouËT, Hubert du, « Division de la propriété noble en Bretagne ", dans Mémoires de la Société d'Histoire et d'Archéologie de la Bretagne (MSHB), 1929, t. X, p. 27-44.

2. Gullhermoz, Paul, Essai sur les origines de la noblesse en France au Moyen Âge, Paris, 1902. 
en revanche, « il n'y a pas à proprement parler, de noblesse, mais des hommes vivant noblement; pas de chevaliers héréditaires, mais des cavaliers servant à la guerre en bel aloi ${ }^{3}$ ".

En ce qui concerne plus spécialement la Bretagne, les actes, que nous avons rencontrés et que nous avons insérés dans notre inventaire sur les hommes d'armes du duché de Bretagne (jusqu'en 1381) ${ }^{4}$, citent bien rarement le terme noble et uniquement pour les plus importants membres de l'aristocratie, ceux qui disposaient d'une fortune imposante en terres, en châteaux et en vassaux, comme par exemple le vicomte de Rohan ${ }^{5}$. Toutefois, il ne faut pas imaginer que les autres seigneurs laïques et ecclésiastiques, que les autres chevaliers et écuyers n'étaient pas connus et reconnus en tant que nobles. Ils l'étaient tellement qu'il était superflu de le mentionner. Ainsi, Henri d'Avaugour, seigneur de Goëlo, de Dinan, de Mayenne et de L'Aigle, héritier de la maison ducale de Rennes, est cité dans les actes en tant qu' " Henri d'Avalgor, chevalier ». Beaucoup de nobles préféraient souvent seulement la simplicité de leur nom à la multiplication des titres.

Il faut aussi remarquer que la fin du XII ${ }^{\mathrm{e}}$ siècle est marquée en Bretagne, comme ailleurs, par l'encadrement de la noblesse. C'est l'époque où les pratiques sociales et militaires étaient encadrées et canalisées par les autorités souveraines. Ainsi, Henri II Plantagenêt, roi d'Angleterre, duc de Normandie et suzerain de Bretagne, aurait défini juridiquement la noblesse de son empire par des enquêtes successives. En fait, comme l'écrit Martin Aurell, "c'est pour tirer profit de ce potentiel militaire que le roi et son entourage dressent la liste des aristocrates puisqu'ils considèrent que tout noble doit être un chevalier ou, tant qu'il n'est pas adoubé, un combattant subalterne ou un écuyer ${ }^{6}$ ". Le fils d'Henri II, Geoffroy Plantagenêt, époux de la duchesse Constance de Bretagne ${ }^{7}$, imita en Bretagne son père en procédant en 1185 à une enquête générale qui eut pour résultat la fameuse Assise au comte Geoffroy. Sans aucun doute, cette Assise voulait réglementer les pratiques successorales de la noblesse bretonne qui, pour des raisons militaires, privilégiait la primogéniture mâle ${ }^{8}$. Toutefois, comme l'a aussi

3. Bloch, Marc, La Société féodale, rééd., Paris, 1989.

4. Thèse préparée sous la direction de Bertrand SCHNERB, intitulée "Les hommes d'armes du duché de Bretagne de 1213 à 1381 ", soutenue en janvier 2007 à l'Université de Lille III.

5. Voir MoRVAn, Frédéric, "Alain VI, vicomte de Rohan, ou les origines de la fortune des Rohan ", dans Bulletin Polymathique du Morbihan, t. CXXXIV, 2008, p. 79-122.

6. Aurell, Martin, L'Empire Plantagenêt, 1154-1224, Paris, 2003, p. 187-189.

7. Voir en fin d'article la généalogie de la maison ducale de Bretagne.

8. AurELl, Martin, L'Empire..., op. cit., p. 189, 199 : Henri II, à l'hiver 1166, produisit les Carte baronum, c'est-à-dire les Livres rouge et noir de l'Échiquier où furent consignés les noms des tenants en chef qui détenaient les plus grands fiefs d'Angleterre, mais aussi le nombre de chevaliers auxquels ces tenants avaient inféodé des terres et avec lesquels ils devaient se rendre à l'ost royal. Une autre enquête fut entreprise en 1172 dans le même but. Elle peut expliquer le soulèvement général que connut l'empire d'Henri II les deux années suivantes. Pour l'Assise, voir Layettes du Trésor des Chartes, Paris, 1863-1902, 
démontré très récemment le juriste Stéphane Morin ${ }^{9}$, les lignages bretons n'avaient pas attendu l'Assise au comte Geoffroy pour éviter la division de leurs patrimoines; avant 1185, il y avait bien sûr déjà eu plusieurs importants partages dans la noblesse bretonne. Elles avaient eu pour origine des motivations politiques et militaires. Ce fut, en effet, sous la contrainte d'Henri II et de son fils, Geoffroy, que les vicomtes de Léon durent partager leurs domaines divisant en deux branches la maison vicomtale, l'ainée dite aussi vicomtale et la cadette, dite des Hervé de Léon ${ }^{10}$. Ces partages vinrent aussi de contingences économiques. Il était difficile de gérer efficacement des patrimoines considérables et dispersés. Ainsi, Alain de Porhoët obtint pour le bonifier le Rohan, soit une portion du Porhoët ${ }^{11}$. Le comte Étienne (maître des Penthièvre et du Trégor en Bretagne et de l'honneur de Richmond en Angleterre) divisa de même ses domaines et donna à son fils aîné, Geoffroy Botherel, le Penthièvre, au cadet, Alain, l'honneur de Richmond, et au troisième, Henri, le Trégor ${ }^{12}$. Il fallait enfin doter en revenus des cadets de bonne famille afin qu'ils puissent tenir leur rang lors des tournois ou à la cour des souverains. Le mot division est le plus souvent impropre car en fait le cadet devenait le vassal de son aîné qui conservait la haute main sur les terres de sa famille. Ainsi à la fin du XII ${ }^{\mathrm{e}}$ siècle, il semblerait que les lignages nobiliaires bretons avaient cessé de diviser leurs patrimoines. Sans doute les " déserts " étaient-ils devenus plus rares en Bretagne à cause certainement de l'expansion démographique.

On aurait pu croire que l'Assise de 1185, dite " au comte Geoffroy ", avait pour seul but de fixer les règles de succession dans l'aristocratie militaire bretonne. En fait, elle avait aussi une grande importance politique. À la différence de son père qui, par son " Assise aux Armes " en 1181, montra ses exigences envers ses barons et chevaliers, Geoffroy fut nettement plus favorable envers les siens. Tout d'abord, l'Assise n'était qu'un texte contractuel et volontaire. Si le baron ou le chevalier ne le voulait pas, il pouvait refuser d'y adhérer et continuer de suivre des règles qui lui étaient propres. Mais s'il l'acceptait, l'acte lui fournissait l'opportunité juridique d'éviter de diviser ses terres et permettait ainsi la sauvegarde du patrimoine dans les mains du fils aîné. Il pouvait donc se reposer sur cet acte juridique afin de repousser la forte pression venant de ses frères cadets ou de ses sœurs. Par ailleurs, par cette Assise, le duc promit de ne plus interférer dans les

t. I, 755-1223 par Alexandre Teulet, 1863, p. 144-145, acte n ${ }^{\circ} 337$ et n ${ }^{\circ} 338$ pour la traduction. L'analyse a été entreprise par PLANIOL, Marcel, L'assise au comte Geoffroi : étude sur les successions féodales en Bretagne, Paris, 1888, réédité 1984 et plus récemment par Everard, Judith, Brittany and the Angevins, Province and Empire, 1158-1203, Cambridge, 2000, p. 182-199.

9. Morin, Stéphane, Recherche sur la destinée de la principauté des comtes de Bretagne (1008-1214), Thèse de doctorat de droit, Rennes, 2004.

10. Kernevez, Patrick et Morvan, Frédéric, "Généalogie des Hervé de Léon (vers 11801363)", dans Bulletin de la Société Archéologique du Finistère, t. CXXXI, 2002, p. 290-312. Voir arbre généalogique de la maison de Léon en fin d'article.

11. Voir en fin d'article l'arbre généalogique de la maison de Porhoët.

12. Voir en fin d'article la généalogie des Eudonides. 
successions, sauf en cas d'absence d'héritier mâle. Surtout, Geoffroy avait des intérêts personnels à élaborer cette Assise. Elle lui permettait de s'emparer des biens des Eudonides dans le Trégor et dans le Penthièvre. Comme nous le savons, l'Assise permettait à une fille d'obtenir tout le fief si elle était enfant unique ${ }^{13}$. Cette décision de Geoffroy allait à l'encontre des usages successoraux des Eudonides qui, depuis le comte Eudes, frère cadet du duc Alain III de Bretagne, pratiquaient la succession selon le régime de primogéniture mâle exclusive. En imposant cet article, Geoffroy pouvait s'emparer des châteaux des Eudonides, châteaux qui auraient dû revenir à son épouse Constance, duchesse de Bretagne, elle aussi une Eudonide, héritière de ce puissant lignage.

Ainsi, tout en fixant des règles successorales qui existaient déjà, le duc Geoffroy contribua au renforcement de l'autorité ducale. Ses successeurs, tout au long du XIII ${ }^{\mathrm{e}}$ siècle, n'oublièrent pas ses méthodes et profitèrent des nombreux conflits de succession pour asseoir leur pouvoir et pour accrồtre leur contrôle sur la Bretagne, sur sa noblesse et son potentiel militaire. Ce fut aussi un moyen très efficace utilisé par les rois de France, à partir du roi Philippe Auguste, pour imposer leur autorité non seulement sur l'aristocratie bretonne, mais aussi sur le duc de Bretagne, car, à partir de 1203, la situation politique changea radicalement. Le pouvoir Plantagenêt qui régnait depuis près d'un demi-siècle sur l'Occident chrétien et sur la Bretagne s'effondra au profit du roi capétien qui imposa sur le trône breton son cousin, Pierre de Dreux. Pierre créa alors en Bretagne une nouvelle dynastie qui eut pour objectif d'accroître son emprise politique, militaire et financière sur le duché afin de répondre à ses grandes ambitions.

Face à cette transformation majeure, la noblesse bretonne, partie intégrante du monde anglo-normand, fut contrainte de s'adapter, et cela non sans quelques difficultés et rébellions comme le révèlent les différents documents issus non seulement des Trésors des chartes des ducs de Bretagne et des rois de France, mais aussi du Parlement de Paris.

Notre attention se portera bien sûr sur les méthodes des princes bretons et français destinées à régler les successions nobiliaires afin de renforcer leur autorité et les réponses que leur firent les nobles concernés par ces règlements. Il est possible de distinguer trois phases dans l'analyse. Tout d'abord, les Capétiens qui arrivèrent en Bretagne profitèrent de certaines successions pour s'imposer. La seconde phase est une période longue puisqu'elle semble débuter vers 1240 et se terminer en 1302. Elle est marquée par l'installation au pouvoir des ducs de Bretagne de la maison de Dreux. Les règlements des successions de la noblesse montrent qu'ils étaient les seuls maîtres de leur duché. À partir de 1302, date de la bataille de Courtrai, le roi de France intervient dans les successions et renforce son autorité en Bretagne.

13. Par contre, si elle avait une ou plusieurs sœurs cadettes, elle n'en avait que les deux tiers, à charge bien sûr pour son époux de rendre le service militaire. 


\section{Les règlements des conflits et l'installation des Capétiens en Bretagne}

Pour commencer, il est possible de distinguer trois moments forts en ce qui concernent l'installation des Capétiens en Bretagne et les conséquences que cela provoqua sur les règlements des successions nobiliaires : la première peut être qualifiée de " choc de 1205 "; la seconde de " choc de 1214 "; la troisième est le problème de la succession de Juhel de Mayenne.

\section{Le choc de 1205}

Le premier capétien à être intervenu dans le règlement des successions nobiliaires en Bretagne n'est pas Pierre de Dreux, mais son cousin et mentor, Philippe II Auguste, roi de France. Ce souverain profita pleinement des querelles intestines et familiales des Plantagenêt pour s'imposer comme l'unique maître non seulement de son royaume de France, mais aussi de la Bretagne. L'assassinat en 1203 d'Arthur I ${ }^{\text {er }}$ Plantagenêt, duc de Bretagne, comte d'Anjou, du Maine et de Touraine, par son oncle, Jean sans Terre, roi d'Angleterre, duc de Normandie, d'Aquitaine et comte de Poitou, souleva la colère des Bretons et permit au roi de France d'obtenir leur aide afin de faire, l'année suivante, la conquête de la Normandie. Le roi de France ne désirant plus de Plantagenêt sur le trône breton ne vit pas d'inconvénient à ce qu'Aliénor Plantagenêt, sœur d'Arthur I ${ }^{\mathrm{er}}$ et prisonnière de Jean sans Terre, fût déshéritée au profit de sa demi-sœur cadette, Alix de Thouars. Il ne voulait certainement pas non plus que la noblesse, bretonne comme normande, continue d'avoir des contacts fréquents avec le monde Plantagenêt. En réponse à la décision de Jean sans Terre qui ordonna en 1204 la confiscation générale des terres de tous ceux qui avaient quitté son service, y compris les établissements religieux, Philippe Auguste répondit que tous ceux qui manqueraient de lui prêter hommage lige avant Pâques 1205 perdraient automatiquement et irrémédiablement leurs possessions dans son royaume. Ces décisions royales eurent des répercussions terribles pour la noblesse bretonne. Il fallut à nombre de lignages du duché revoir leurs pratiques successorales afin de préserver leur fortune. Ils procédèrent à des partages, sans doute sous forme d'avances sur héritage, dans l'urgence, en espérant que les ordonnances royales, anglaises et françaises, ne seraient, comme auparavant, que temporaires. Ainsi, Harsculf de Subligny, qui avait rejoint le parti de Jean sans Terre dans les îles anglo-normandes, émancipa son fils Jean III, et lui laissa gérer les biens lui venant de sa mère, Iseult de Dol, soit la seigneurie de Combourg. Quant à lui, il conserva et augmenta ses domaines en Angleterre. Toutes ses terres et même celles de son fils, pourtant fidèle au roi de France, furent confisquées par Philippe Auguste. Peu après, Jean de Dol retrouva ses terres, mais les fiefs anglais de la famille passèrent à son frère cadet, Raoul (jusqu'en 1241), puis au fils de celui-ci, André 
(jusqu'en 1259), puis à Geoffroy, clerc, frère de Jean (jusqu'en 1265) ${ }^{14}$ (Cf. annexe 1 - La succession d'Harcoul de Subligny).

De nombreux lignages de Bretagne se divisèrent. Le lignage de Porhoët se divisa ainsi de nouveau ${ }^{15}$. Vers 1203 , Roger de La Zouche, un cadet de la maison de Porhoët, décida de faire don à son cousin, le vicomte de Rohan, de toutes ses possessions en Bretagne, sans doute en échange des domaines anglais des Rohan, soit les terres de Swavesey et de Fulbourn ${ }^{16}$. Olivier, sénéchal héréditaire de Dol, quant à lui, s'installa définitivement en Angleterre dans ses terres des Marches galloises laissant à sœur, Alice, sa fonction héréditaire en Bretagne, qu'elle transmit à son époux, Guillaume de L'Espine. Les Dinan se séparèrent aussi de leurs biens alors en indivision. La branche issue d'Olivier, troisième fils de Geoffroy II de Dinan (mort en 1159), resta en Angleterre et se consacra à l'administration de ses biens dans le Devon et dans le Somerset. Elle fut à l'origine des lords Dinham. Il semblerait de même que Guillaume d'Aubigné, connu sous le nom de Guillaume Albini Brito, seigneur de Belvoir, préféra rester en Angleterre où ses intérêts étaient plus importants qu'en Bretagne. Il était proche parent des comtes de Surrey, d'Arundel et de Norfolk. Peut-être laissa-t-il à son fils aîné la terre bretonne d'Aubigné puisqu'un Guillaume d'Aubigné aurait été dans l'ost de Guy de Thouars, puis dans celui de Pierre de Thouars en 1204. Mais on peut en douter car ce même Guillaume était en 1215 en Angleterre où il est cité comme un des principaux garants de la Grande Charte ${ }^{17}$. Il semblerait, sans que nous en connaissions la date, que ce fut la sœur de ce dernier, Stéphanie, qui ait obtenu la seigneurie d'Aubigné. D'autres nobles bretons eurent un comportement identique et dotèrent largement leurs filles, quitte ensuite, lorsque les temps auraient été meilleurs, à les dédommager afin de récupérer leurs biens. Ainsi, Pierre Boterel, vassal important de l'honneur de Richmond pour ses fiefs d'East Witton et de Nettlestead (Suffolk) ${ }^{18}$ donna ses biens en Bretagne à sa fille lors de son mariage avec le breton Jean de Maignen.

Pour éviter la colère des nobles bretons qui avaient perdu beaucoup en Angleterre lors de ces confiscations, Philippe Auguste décida de compenser en agissant considérablement sur les successions nobiliaires. Guillaume de Fougères, cadet du seigneur de Fougères, avait reçu en partage les biens

14. POWER, Daniel, « Terra regis Anglie et terra Normannorum sibi invicem adversandur : les héritages anglo-normands entre 1204 et 1244 ", dans La Normandie et l'Angleterre au Moyen Âge, colloque de Cerisy-la-Salle, 3-7 octobre 2001, éd. V. GAZEAU, 2004, avec un arbre généalogique p. 203.

15. Voir l'arbre généalogique des Porhoët en fin d'article.

16. Médiathèque de Nantes, fonds Bizeul, $\mathrm{n}^{\circ}$ 1701, fr. 1545.

17. Holt, James C., Magna Carta, Cambridge, reéd. 2003, p. 82, 101, 291, 356, 411, 478, 485,511 .

18. En 1226, la terre de Nettlestead dans le Suffolk fut déclarée terra Britonis, en faveur de Peter Boterel, descendant de Geoffroy Fitz Aimeric. Sa descendance continua de posséder des terres en Angleterre jusqu'en 1242 (Katherine KEATs-RoHaN, "Two Studies in North French Prosopography ", op. cit., p. 34-37). 
anglais de sa famille ${ }^{19}$. En janvier 1203, ses terres furent saisies. En compensation, le 25 juillet 1204, devant la cour de Guy de Thouars, comte ou duc de Bretagne (pour l'administration royale, le duc de Bretagne n'était que comte), il fut décidé de permettre à Guillaume de disposer de ses propres revenus indépendamment de ceux du seigneur de Fougères, sans doute afin qu'il puisse tenir son rang de chef de guerre issu d'un haut lignage. Son neveu Geoffroy devait lui laisser en viager la terre de Coglès dans son intégralité, une rente de 100 livres de terre à prendre à Marcillé et aux alentours, les droits sur la forêt de Fougères et, s'ils étaient restitués, les manoirs anglais. En contrepartie, Guillaume devait, si le comte de Bretagne levait son armée, aider son neveu en fournissant des chevaliers ${ }^{20}$. Pour la première fois, cet accord fut ratifié le mois suivant par le roi de France à Châtellerault ${ }^{21}$. Comme aucun bien anglais n'avait été restitué, le roi montra encore son autorité en 1209 en contraignant Guillaume de Fougères à renoncer à $80 \%$ de sa rente qui fut réduite à 20 livres $^{22}$. Guillaume fut bien forcé d'accepter ce sacrifice car le système de succession employé par les Fougères afin de sauvegarder entre les mains du seigneur de Fougères leur fortune anglaise avait échoué. En effet, comme l'a révélé Nicholas Vincent, les manoirs anglais des Fougères qui avaient été confisqués par le roi d'Angleterre furent confiés à Ranulf d'Avranches, comte de Chester et de Lincoln, époux de Clémence de Fougères, mais aussi à Raoul de Meulan, fils d'une Fougères, et à Guillaume de Saint-Jean. Certains manoirs restèrent jusqu'en 1248 entre les mains de la comtesse de Chester, puis furent saisis en 1248, à sa mort, par le souverain anglais ${ }^{23}$. Jamais le seigneur

19. En octobre 1200 , lors d'un premier accord, Guillaume confirma à son neveu Geoffroy de Fougères la possession de la cité de Fougères et des terres que la famille détenait dans le comté de Mortain en Normandie et qui servaient de dot à Clémence, comtesse de Chester. Guillaume devait payer à Clémence 100 livres angevines. Au bout de cinq ans, il devait restituer à Geoffroy ses biens à Fougères tout en gardant pour lui les manoirs de Twyford, West Kington et Bennington en Angleterre.

20. Bibliothèque nationale de France (BnF), fonds français 22330, p. 3 ; Cartulaire de la seigneurie de Fougères, connu sous le nom de Cartulaire d'Alençon, éd. Jacques AuBERG, Rennes, 1913 (Car. d'Alençon), p. 163-165, acte n XLII; et Dom Hyacinthe MoRICE, Mémoires pour servir de preuves à l'histoire ecclésiastique et civile de Bretagne, 3 vol., Paris, 1742-1746 (Dom Morice, Pr., t. I), col. 798.

21. Catalogue des actes de Philippe Auguste, par Léopold DeLisLe, Paris, 1856, p. 192, $\mathrm{n}^{\circ}$ 845; Dom MoRICE, Pr., t. I, col. 798.

22. BnF, fonds français 22330, p. 4; Dom MoRICE, Pr., t. I, col. 810; Cartulaire d'Alençon, op. cit., p. 165-168, acte ${ }^{\circ}$ XLIII-XLIV; Catalogue des actes de Philippe Auguste, op. cit., p. 297, $\mathrm{n}^{\circ} 1000$.

23. En effet, le manoir de Bennington dans le Lincolnshire, saisi sur Guillaume de Fougères, fut conféré à Ranulf de Chester, beau-frère de Raoul III. Ranulf récupérait ainsi la dot de son épouse. Il reçut aussi les terres des Fougères à Twyford, West Kington dans le Wiltshire et Osmundiston dans le Norfolk. En 1221, Ranulf obtint les terres de Scartho et de Limber dans le Lincolnshire qu'avaient eues Guillaume de Fougères. Ippleden dans le Devon passa encore au comte de Chester et à Raoul de Meulan, fils d'une Fougères. À la mort du comte de Chester, en 1232, les manoirs de West Kington et de Twyford furent donnés à des Anglais ayant des liens étroits avec la maison de Fougères. Ainsi, ils passèrent à Richard Le Maréchal, époux de Gervaise de Dinan, fille d'Alain de Dinan, 
de Fougères ou son oncle, Guillaume, n'eut l'opportunité de retrouver les importants manoirs et domaines anglais de la famille (annexe 2 : Généalogie des seigneurs de Fougères).

Par ailleurs, Philippe Auguste intervint encore dans l'importante succession de Geoffroy III Boterel, comte de Penthièvre ou de Lamballe.

Avant de mourir en 1205, Geoffroy III Boterel, comte de Penthièvre ou de Lamballe, devant le roi de France et avec l'accord de ce dernier, avait légué à Alain de Tréguier, ses domaines et châteaux, dont ceux de Jugon, Lamballe et Moncontour ${ }^{24}$. Geoffroy ne faisait qu'appliquer les règles de succession des Eudonides. Il semblerait que comme Geoffroy II Plantagenêt, Guy de Thouars, régent du duché, n'ait pas accepté de voir sa fille, la duchesse Alix, déshéritée comme l'avait été sa mère, Constance de Bretagne. Un acte publié par Anatole de Barthélémy démontre que Guy de Thouars avait réussi à récupérer Jugon puisqu'il le possédait en 1205, c'est-à-dire après que Philippe II Auguste eût accordé le comté de Lamballe à Alain de Tréguier. Ce document mentionne en effet la confirmation par Guy d'une donation de la duchesse Constance à l'abbaye de Boquen. Un des témoins de l'acte est un certain Rivallon, fils de Cari, sénéchal de Penthièvre, c'està-dire qu'il administrait la région de Lamballe et de Jugon pour le compte de Guy ${ }^{25}$. Par ce comportement, Guy de Thouars s'aliéna non seulement la confiance du roi de France car le régent de Bretagne lui avait désobéi, mais aussi celle d'Alain de Tréguier, puissant seigneur qui avait participé activement à la conquête de la Normandie et qui pour cela avait perdu son important fief anglais, "le soke of Waltham ". Il est très vraisemblable que Philippe Auguste a voulu compenser cette perte en accordant à Alain la succession de son cousin ${ }^{26}$. Il est encore probable qu'en opérant ainsi le roi se détachait de Guy de Thouars dont le frère, le vicomte de Thouars, se rapprochait alors dangereusement du roi d'Angleterre. Le conflit risquant

premier époux de Clémence de Fougères. Les terres qu'avait Guillaume de Fougères à Birdham dans le West Sussex et Merrow dans le Surrey furent données à Guillaume de Saint-Jean, proche parent des Fougères. Les manoirs de Bennington et de Foston furent saisis uniquement en 1248, à la mort de Clémence de Fougères, comtesse de Chester (VINCENT, Nicholas, " Twyford under the Bretons, 1066-1250 ", dans Nottingham Medieval Studies, vol. XLI, 1997, p. 80-99).

24. LA BORDERIE, Arthur de, Nouveau recueil d'actes inédits des ducs et princes de Bretagne (XII ${ }^{e}$-XIV ${ }^{e}$ siècles), Rennes, 1902, témoins de l'enquête de 1235, $\mathrm{n}^{\circ}$ 5-27.

25. BARTHÉLÉMY, Anatole de, Enquête faite en 1235 sur les droits d'Henri d'Avaugour, 1873, t. 33, p. 344; EVERARD, Judith, JONES, Michael, The Charters of duchess Constance of Brittany and her Family, 1171-1221, Woodbridge, 1999, p. 149-150 (Gu 10), acte de 1205.

26. Le soke de Waltham, n'était pas un petit fief. Il rapportait tout de même plus de 100 livres anglaises de revenus annuels, soit un septième de l'honneur de Richmond c'est-à-dire l'un des cinq fiefs les plus importants d'Angleterre. CLAY, Charles Travis, Early Yorkshire Charters, vol. IV, The Honour of Richmond, part I, Wakefield, 1935, p. 88 mentionne : « in the accounts of the honour of Richmond at Michaelmas 1183 Ranulf de Glanville accounted for $55 \mathrm{l} .16 \mathrm{~s}$. 8d. for the farm of Waltham, Lincs., being the land of Alan, son of count Henry for half the year "; "In 1192, the sheriff accounted for his land for a full year the amount being double the sum mentioned above". 
de s'envenimer rapidement entre Alain de Tréguier et Guy de Thouars, en 1206, à Candé en Anjou, le roi de France divisa en deux parties la Bretagne : Guy de Thouars reçut le sud du duché, soit en fait les revenus des domaines ducaux situés dans les évêchés de Cornouaille, de Vannes et de Nantes; Alain de Tréguier, cité dans l'acte comme le comte Alain, obtint le nord de la province, soit les revenus des évêchés de Saint-Malo, de Dol, de SaintBrieuc et de Léon. Alain devait pouvoir en plus récupérer sans problème la succession de son cousin, Geoffroy III Boterel, et réunir ainsi tous les domaines bretons de son grand père, le comte Étienne, soit le Trégor et le Penthièvre. En même temps, il fut décidé que son fils aîné, Henri, qui devait hériter des droits des Eudonides sur le trône de Bretagne, épouserait la duchesse Alix de Thouars. Philippe Auguste reconnaissait ainsi les droits des Eudonides sur le trône breton ${ }^{27}$. Toutefois, en 1212, la situation politique changea une nouvelle fois. La guerre entre les monarchies capétienne et plantagenêt menaçait de reprendre. Par ailleurs, l'accord établi à Candé par le roi de France tomba en poussière lorsque le comte Alain décéda ne laissant qu'un fils mineur. Selon l'accord, Guy de Thouars aurait dû remplacer Alain, mais lui aussi disparut, quelques mois plus tard, en avril $1213^{28}$ (Cf. annexe 3 - La succession des Eudonides).

Le roi aurait pu se tourner vers André II de Vitré, fidèle aux Capétiens, dont le fils, André III, épousa Catherine de Thouars, sœur cadette d'Alix. Toutefois, lui aussi mourut vers 1211/1212, ne laissant donc qu'un fils alors mineur. Qui restait-il pour diriger la Bretagne et l'ost breton qui devait être réuni afin de faire face à Jean sans Terre? Juhel III de Mayenne semble avoir voulu se placer sur les rangs ${ }^{29}$. Seigneur de Mayenne par droit propre, de Dinan-sud, de Léhon et de Bécherel de par les droits de son épouse, Gervaise de Vitré, tuteur des seigneurs de Fougères, de Vitré et de Laval, il prit donc le titre de sénéchal de Bretagne qu'il considérait comme héréditaire puisque son beau-père, Alain de Vitré, seigneur de Dinan, l'avait eu sous les Plantagenêt ${ }^{30}$. Voulut-il faire comme son parent, Guillaume des Roches, alors sénéchal héréditaire d'Anjou, du Maine et de Touraine? Peutêtre, mais le roi de France ne le souhaita pas. Sans doute le souverain ne voulut-il pas que le lignage de Juhel contrôle tout le nord-ouest du royaume. Par ailleurs, Juhel n'avait pas de fils à marier à Alix de Thouars et aurait donc eu des difficultés afin d'obtenir la reconnaissance de l'ensemble de la noblesse bretonne. Philippe Auguste choisit en fin de compte son cou-

27. Dom Morice, Pr., t. I, col. 807; Berger, Élie, Delaborde, Henri-François, Monicat, Jacques et Boussard, Jacques, Recueil des Actes de Philippe Auguste, 3 vol., Paris, 1916 et 1966, n ${ }^{\circ} 939$ et ÉVERARD, Judith, Brittany and the Angevins..., op. cit., p. 136.

28. Everard, Judith, Jones, Michael, The Charters of duchess Constance..., op. cit., p. 136.

29. Voir l'arbre généalogique de Juhel de Mayenne en fin d'article.

30. Voir l'acte de Juhel de Mayenne, seigneur de Dinan, sénéchal de Bretagne, confirmant à l'abbaye de Beaulieu, après avoir lu les lettres de franchises, les foires de Plumaudan (Archives départementales des Côtes-d'Armor [Arch. dép. des Côtes-d'Armor], H 5, abbaye de Beaulieu, original, parchemin). 
sin, Pierre de Dreux, arrière-petit-fils de Louis VI le Gros, afin de diriger la Bretagne et commander la noblesse bretonne qui devait arrêter Jean sans Terre qui remontait à travers le Poitou depuis La Rochelle en direction de la Normandie. Le roi d'Angleterre était alors accompagné par Aliénor Plantagenêt, prétendante au trône de Bretagne en tant que fille aînée de la duchesse Constance. Le roi de France savait Pierre de Dreux particulièrement apte au métier des armes puisqu'il l'avait armé personnellement chevalier à Compiègne. Il maria donc dans l'urgence Pierre à Alix de Thouars. Le roi ne s'était pas trompé puisque Pierre fut victorieux devant Nantes ${ }^{31}$ et à La Roche-aux-Moines. Philippe Auguste ne pouvait alors plus rien lui refuser.

\section{Le choc de 1214}

L'objectif de Pierre de Dreux fut ensuite de s'imposer dans son nouveau fief, un des plus importants du royaume de France. Il profita de deux successions, toujours celle des Eudonides et celle de Juhel de Mayenne. Comme le duc Geoffroy II Plantagenêt et le régent Guy de Thouars, Pierre de Dreux refusa les pratiques successorales des Eudonides et s'empara au nom de son épouse, Alix, héritière des Eudonides, de tous les châteaux et les fiefs d'Henri, fils d'Alain, alors mineur, dans le Trégor et le Penthièvre ${ }^{32}$. Pierre ne lui laissa que les fiefs patrimoniaux de son père, soient les Goëlo et Quintin. Selon un témoignage de 1247, Henri perdit de ce fait une terre valant 4000 sous de rente ${ }^{33}$. Son oncle et tuteur, Conan, vicomte de Léon, se révolta. Mal lui en prit car Pierre l'attaqua et s'empara de Lesneven, place forte principale de la maison de Léon. Un acte d'août 1216 de l'évêque de Léon montre que Conan avait en effet perdu Lesneven; il y est mentionné que les duc et duchesse de Bretagne détenaient cette cité puisqu'ils donnèrent la paroisse de Saint-Michel de Lesneven à l'abbaye ducale de SaintSulpice de Rennes afin d'y fonder un prieuré ${ }^{34}$. Quelques mois plus tard, en octobre 1216, le duc donna encore à cette même abbaye l'église de SainteMarie de Lesneven ${ }^{35}$. Les vicomtes de Léon, appelés aussi par Guillaume Le Breton, les Leonenses, en furent réduits à fuir leurs châteaux et à mener

31. Dom Morice, Pr., t. I, col. 857-858.

32. Voir l'arbre généalogique des Eudonides en fin d'article.

33. Recueil des Historiens de France, t. XXIV, p. 729-731.

34. Archives départementales d'Ille-et-Vilaine (Arch. dép. d'Ille-et-Vilaine), 2 H 2, 86 ; ibid., 24 H 109, fonds de l'abbaye de Saint-Sulpice, une transcription de 1754 y est jointe; Cartulaire de l'abbaye de Saint-Sulpice-la-Forêt, éd. Dom ANGER, Rennes (publié dans Bulletin de la Société d'Archéologie d'Ille-et-Vilaine (BSAIV), t. XXXV-XLI, 1905-1911) (Cart. St-Sulpice), op. cit., p. 10-11, acte n ${ }^{\circ}$ LXXXVIII et LA BORDERIE, Recueil d'actes inédits..., op. cit., p. 163, n 91; LEVRON, Jacques, Catalogue des actes de Pierre de Dreux, précédé d'une introduction sur l'organisation administrative de la Bretagne au début du XIII e siècle, Rennes, 1931, p. $36, \mathrm{n}^{\circ} 33$.

35. Arch. dép. d'Ille-et-Vilaine, 2 H 2, 86 ; Cart. St-Sulpice, op. cit., t. XXXVII, p. 172; LEVRON, Jacques, Catalogue des actes de Pierre de Dreux, op. cit., p. $36, \mathrm{n}^{\circ} 32$. 
du fond de leurs forêts une guérilla contre les agents ducaux ${ }^{36}$. Henri de Goëlo, qui prit le nom d'Henri d'Avalgor ou Avaugour, se réfugia à Dinan chez Juhel de Mayenne qui lui donna la main de sa fille cadette, Marguerite. En fait, il semblerait que Pierre ${ }^{\mathrm{er}}$ en ait seulement profité pour s'emparer des principaux châteaux du Trégor et du Penthièvre, alors entre les mains d'Henri d'Avaugour, et ait laissé à la sœur de Geoffroy III Boterel, comte de Penthièvre, Eline, la forêt de Lamballe et des droits situés de part et d'autre de la baie de Saint-Brieuc ${ }^{37}$. Il est aussi vraisemblable que le duc Pierre se soit appuyé sur le mari et le fils d'Eline, Geoffroy et Olivier Tournemine, afin de s'imposer dans le Penthièvre. Le duc leur donna ainsi la fonction de sénéchal de Penthièvre, mais aussi le droit de construire le château de La Hunaudaye juste en face des fiefs bretons de Juhel de Mayenne. Pierre de Dreux utilisait cette méthode pour surveiller Juhel de Mayenne car il ne pouvait alors rien contre lui : Juhel contrôlait en effet toutes les marches normano-bretonnes au nom du roi de France.

En effet, depuis août 1210, Juhel de Mayenne avait obtenu du roi de France le château du Guesclin qui protégeait Dinan des incursions venant de la mer ${ }^{38}$. Avec le château de son épouse à Léhon et celui de Pontorson que le roi Philippe Auguste lui avait donné, il empêchait tout débarquement anglais au nord-est du duché. Par ailleurs, il contrôlait un vaste territoire englobant le nord-est de la Bretagne, autour des fiefs de son épouse et de ses pupilles, les jeunes seigneurs de Vitré, de Fougères et de Goëlo, le sud du Cotentin autour de Pontorson, et tout le nord du Maine, autour de ses propres domaines de Mayenne, ceux de son demi-frère, le seigneur de Craon et ceux de son pupille, le seigneur de Laval. Outre les forteresses qui s'y trouvaient, Juhel de Mayenne disposait de plusieurs centaines de vassaux, c'est-à-dire d'autant d'hommes d'armes qui amenaient avec eux toute leur puissance militaire (Cf. annexe 4 - La parenté de Juhel de Mayenne).

\section{La question de la succession de Juhel de Mayenne}

Pierre de Dreux devait donc attendre son heure car Juhel de Mayenne était alors âgé et n'avait eu que des filles. En 1220, Juhel de Mayenne mourut laissant un grand vide. Pourtant, le duc Pierre de Bretagne ne reçut pas l'autorisation du roi pour prendre possession des châteaux du Guesclin et de Pontorson. Pierre n'avait plus alors toute la confiance du roi, Henri III d'Angleterre lui ayant restitué ses biens anglais, soit le très important honneur de Richmond. Philippe Auguste fit appel pour commander la forteresse et la garnison de Guesclin à Amaury de Craon, le demi-frère de Juhel

36. Le Breton, Guillaume, Philippide, éd. Henri-François Delaborde, 1885, t. II, p. 362363.

37. Arch. dép. des Côtes d'Armor, E 104; Anciens évêchés, éd. Jules Gesuin de BouRGoGNE et Anatole de BARTHELEMY, Saint-Brieuc et Paris, 1855-1879 (A.E.), t. V, p. 14.

38. Pour la place du Guesclin, il promit au comte de Nantes de lui envoyer à Jugon deux chevaliers d'ost (Dom Morice, Pr., t. I, col. 136-137). Voir aussi Power, Daniel, The Norman Frontier in the Twelfth and Thirteenth Centuries, Cambridge, 2004, p. 461. 
de Mayenne, beau-fils et héritier de Guillaume des Roches, seigneur de Sablé et sénéchal du Maine et d'Anjou ${ }^{39}$. Amaury avait par ailleurs au cœur du duché, par la grâce du roi de France, la terre de Ploërmel. Le conflit avec le souverain breton était alors imminent car Pierre de Dreux menait une politique expansionniste dans le comté de Rennes. Il s'était en effet emparé des châteaux des lignages de Dinan-Montafilant ${ }^{40}$, de Dol et de Fougères, mais aussi de la forêt de Rennes, dot de sa belle-sœur, Catherine de Thouars, dame de Vitré de par son mariage ${ }^{41}$. Amaury de Craon, qui semble s'être présenté comme le successeur de Juhel de Mayenne, profita en octobre 1221 de la mort d'Alix de Thouars pour agir. La position de Pierre I ${ }^{\text {er }}$ était alors fragilisée. Il n'administrait plus le duché de Bretagne qu'au nom de ses trois enfants mineurs et cela jusqu'à leur majorité ${ }^{42}$. Surtout, le 14 juillet 1223, Pierre perdit son plus fidèle soutien car Philippe Auguste disparut. Malgré tout, le nouveau roi, Louis VIII, était un proche de Pierre de Dreux. Amaury devait agir au plus vite en profitant du changement de souverain. Il était alors le plus important seigneur du nord-ouest du royaume de France. Il réunit les troupes de l'Anjou et du Maine en tant que sénéchal héréditaire de ces régions. Il obtint l'intervention militaire de Jean, comte de Vendôme, et d'Hardouin de Maillé. Non seulement Jean de Montoire, comte de Vendôme, de 1218 à 1230, était le cousin d'Henri d'Avaugour, mais de plus son fils et héritier, Pierre, était marié à Jeanne de Mayenne, dame de Lassay et de La Châtre-sur-le-Loir, troisième fille de Juhel de Mayenne et de Gervaise de Dinan, et donc belle-sœur d'Henri d'Avaugour. Le soutien d'Hardouin de Maillé est intéressant car il permet de constater que le duc Pierre avait aussi mécontenté la noblesse du pays nantais puisqu'Hardouin de Maillé était l'époux de Jeanne de Thouars, dame de La Roche-sur-Yon, de Luçon dans le Poitou et surtout de Machecoul en Bretagne. Sans doute, Hardouin n'appréciait guère les agissements de Pierre qui commençait à se constituer un fief important à son propre profit dans la région des Marches Sud de la Bretagne. Le 3 mars 1222, grâce à l'appui d'une partie de la noblesse bretonne, dont certains pupilles de Juhel de Mayenne qui ne devait guère apprécier Amaury de Craon. Ce dernier et ses alliés furent défaits à la bataille de Châteaubriant. Les vaincus furent emprisonnés. En fin de compte Pierre de Dreux put récupérer la terre de Ploërmel et être le seul maître du duché de Bretagne.

39. Catalogue des actes de Philippe Auguste, op. cit., p. 447, n 2017.

40. En 1218, Geoffroy Prigent mentionna qu'au temps où il fut sénéchal de noble homme Pierre, comte de Bretagne, dans toute la terre de Rolland de Dinan, il avait attesté de l'accord entre Geoffroy Batelle et les moines de Boquen, au sujet de la vigne de Sévignac que les moines avaient dans le fief de Geoffroy Batelle (Arch. dép. des Côtes d'Armor, $\mathrm{H} 210$, parchemin déchiré dans le coin gauche et au sommet, $15 \mathrm{~cm}$ x 11,5 cm; A.E., t. III, p. $\left.232-233, \mathrm{n}^{\circ} \mathrm{XXIV}\right)$.

41. Dom Morice, Pr., t. I, col. 850; BerTRAND de Broussillon, A., La maison de Laval, 10201605, 5 vol., Laval, 1895-1903, t. I, p. 213.

42. Dom Morice, Pr., t. I, col. 107. 
L'ensemble de la noblesse bretonne semblait alors avoir accepté le baillistre ou régent du duché. En fait, il n'en fut rien car elle aussi attendait son heure. Dès 1230 , elle profita de la rébellion de Pierre de Dreux, qui prétendait à la régence du royaume de France à la place de Blanche de Castille, pour se révolter et faire appel au roi de France. Le jeune roi, Louis IX, intervint militairement afin de soumettre le régent de Bretagne qui l'avait défié et qui s'était allié au roi d'Angleterre. Abandonné par Henri III d'Angleterre, Pierre de Bretagne fut contraint de se soumettre et sembla perdre les quelques avantages qu'il avait obtenus sur la noblesse bretonne. Le roi paraît avoir permis la revanche des nobles bretons à Crépy-en-Valois en juin 1235. Tout d'abord, la succession d'Eudes III, vicomte de Porhoët, fut réglée devant lui ${ }^{43}$. Louis IX et sa mère y attestèrent de l'accord entre Raoul III de Fougères et Guy IV Mauvoisin, puissant seigneur normand de Rosny, concernant les terres qu'avaient eues le comte Eudes (de Porhoët) et son fils, Eudes, dans toute la Bretagne. En présence de Pierre de Dreux, qui ne fit qu'acquiescer, Guy renonça à une partie de son héritage lui venant de son épouse, Alix de Porhoët, tante d'Eudes III, contre 2500 livres tournois assignées par trois chevaliers sur les rentes qu'avait Raoul en Normandie, soit le fief relevant du comte de Boulogne et celui dépendant de l'abbaye du Mont-Saint-Michel; si cela n'était pas suffisant, la rente devait être assise sur le fief relevant du roi de France ${ }^{44}$. De plus, Raoul de Fougères, car il avait accepté de faire la paix avec le duc de Bretagne, obtint la liberté de rachat, de bailli et de garde dans ses terres de Bretagne ${ }^{45}$. Ainsi, il n'avait plus à payer le rachat féodal lors d'une succession. De même, toujours à Crépy, à la même date, le plus important ennemi de Pierre de Bretagne, son beaufrère, André III de Vitré, obtint la belle terre et le beau château d'Aubigné près de Rennes en compensation de tout ce qu'il avait perdu, de la dot de son épouse Catherine de Bretagne et surtout des fortifications réalisées sur ordre du duc à Rennes et à Saint-Aubin-du-Cormier. André de Vitré eut non seulement le droit de fortifier ses châteaux, de ne pas envoyer à l'ost ducal ses chevaliers, mais aussi la protection du roi pour l'ensemble de ses terres. Si le duc de Bretagne osait encore se rebeller contre le roi de France, le seigneur de Vitré avait le droit de se rebeller contre lui ${ }^{46}$. Enfin, le seigneur de Vitré reçut l'hommage direct de trois seigneurs les plus importants du comté de Rennes, le riche évêque de Dol, Alain d'Acigné et Jean de Dol, seigneur de Combourg ${ }^{47}$ qui reçurent aussi l'exemption de rachat. André de Vitré devint le maître d'une entité territoriale quasi-indépendante au

43. Voir l'arbre généalogique des Porhoët en fin d'article.

44. Arch. nat., J 241, ${ }^{\circ} 13$; Dom Morice, Pr., t. I, col. 890-891; Layettes du Trésor des Chartes, t. II, 1223-1246, p. 294-295, n 2389; Cartulaire normand de Philippe Auguste, Louis VIII, Saint Louis et Philippe le Hardi, publié par DeliSLE, Léopold, Caen, 1852, p. 68, nº 416. 45. BnF, ms. français 22319, château de Vitré, p. 147-148; LA BORDERIE, Arthur de, Recueil d'actes inédits..., $\mathrm{n}^{\circ}$ 108; Dom Morice, Pr., t. I, col. 903, publication partielle; BERTRAND de BRoussillon, A., op. cit., t. I, p. 27-228, n 395.

46. LA BORDERIE, Arthur de, Recueil inédits..., op. cit., n CVII, p. 177.

47. Arch. dép. de Loire-Atlantique, E 161, n 1, LA BORDERIE, Arthur de, Recueil inédit..., op. cit., $\mathrm{n}^{\circ} \mathrm{CX}, \mathrm{p}$ 183-18. 
nord-est du comté de Rennes. Par ailleurs, toujours en 1235, une enquête royale fut menée ayant pour objectif d'estimer les pertes d'Henri d'Avaugour ${ }^{48}$ et certainement pour lui permettre de retrouver les terres de son père. Toutefois, Pierre de Dreux prit le roi de France au dépourvu en se croisant ${ }^{49}$ et en donnant en dot le Penthièvre à sa fille Yolande lors de son mariage avec le puissant Hugues de Lusignan, comte d'Angoulême. Il était donc hors de question pour le roi de France de retirer le Penthièvre à ce grand seigneur poitevin.

Il faut remarquer à ce stade que le roi de France et le duc de Bretagne, pour imposer leur autorité, s'immisçaient avec efficacité, dans les règlements de succession nobiliaire. Néanmoins, le roi de France montrait sa supériorité en arbitrant les conflits et surtout en retirant au duc de Bretagne, lorsqu'il se rebellait, une partie de son pouvoir en réglant directement les successions essentielles au gouvernement de la Bretagne, comme celle de Porhoët, mais aussi en retirant au duc de Bretagne son droit d'exiger le rachat sur d'autres importantes seigneuries que celles de Fougères, de DolCombourg et de Vitré.

\section{Les règlements des conflits de succession, instruments du renforcement du pouvoir ducal (vers 1240-1302)}

La situation politique changea encore une nouvelle fois en 1237 avec l'accession au pouvoir de Jean I Ir, fils de Pierre de Dreux et d'Alix de Thouars, qui avait atteint sa majorité, et dont la légitimité ne fit plus de doute en 1242 à la mort de sa tante, Aliénor. Pendant tout le reste du XIII ${ }^{\mathrm{e}}$ siècle, lui et ses descendants profitèrent de certaines successions difficiles au sein de la noblesse bretonne afin de s'imposer définitivement et d'accroître leurs domaines et leur pouvoir sans que le roi de France n'intervienne aucunement. Les ducs de Bretagne étaient devenus alors des éléments trop importants dans le concert diplomatique. En effet, Jean I ${ }^{\mathrm{er}}$, en épousant Blanche, fille de Thibaud, comte de Champagne et roi de Navarre, obtint l'essentiel du comté du Perche et des droits sur la Navarre et la Champagne. Il devint même l'oncle du roi de France, Philippe IV le Bel. Jean II, son fils,

48. L'original de cette enquête de 1235 si importante pour l'histoire de la Bretagne du XIII ${ }^{\mathrm{e}}$ siècle est conservé aux Archives nationales de France (Arch. nat., J 240, n 36 , avec une copie en J 241 ${ }^{\mathrm{A}}, \mathrm{n}^{\circ}$ 29) et a été publiée par Dom Guy-Alexis LOBINEAU, Histoire de Bretagne, 2 vol., Paris, 1707, t. II, col. 387, par A. Teulet, Layettes..., op. cit., t. II, p. 303, $\mathrm{n}^{\circ}$ 2418, partiellement par LA BORDERIE, Arthur de, Nouveau recueil d'actes inédits des ducs et princes de Bretagne (XII ${ }^{e}$-XIV ${ }^{e}$ siècle), Rennes, 1902, p. 9-17; partiellement encore par Dom Morice, $P r$., t. I, col. 885-888. Toutefois, la publication la plus complète de l'enquête de 1235 a été réalisée par ARCHER, John, Une analyse du développement des pouvoirs des ducs de Bretagne auprès de leurs vassaux (1203-1305), mémoire de maîtrise sous la direction d'Hervé Martin, Rennes II, 1996, annexes. Pour des analyses détaillées de cette enquête, il faut aussi se reporter à BARTHELEMY, Anatole de, Enquête faite en 1235 sur les droits d'Henri d'Avaugour, 1873, t. 33, p. 336 et à John ARCHER, Une analyse..., op. cit.

49. PocQuet du Haut-Jussé, Barthélémy-Anatole, Les papes et les ducs de Bretagne. Essai sur les rapports du Saint Siège avec un État, Paris, 1928, rééd. 2000, p. 119. 
entretint d'excellentes relations avec le roi d'Angleterre, Edouard I ${ }^{\mathrm{er}}$, son beau-frère, qui avait pris en charge l'éducation de son neveu, le prince Jean de Bretagne (futur comte de Richmond). Ces alliances permirent aux ducs à la fois d'échapper à l'emprise des rois de France et d'Angleterre et d'être indispensable à l'un comme à l'autre. Disposant d'une puissance financière, administrative et militaire inégalés jusqu'alors, les ducs de la maison de Dreux intervinrent efficacement dans les successions nobiliaires.

Même s'il est possible de distinguer une date marquante dans l'évolution des pratiques successorales de la noblesse bretonne car en janvier 1275 Jean I $^{\text {er }}$ passa des conventions avec ses principaux vassaux afin de changer le droit de bail en droit de rachat permettant à ceux-ci de ne payer qu'une année de revenu ${ }^{50}$, il faut tout de même remarquer que deux périodes apparaissent : l'une dominée par la personnalité de Jean I ${ }^{\mathrm{er}}$, l'autre par son fils, le duc Jean II.

\section{Les interventions du duc Jean I ${ }^{e r}$}

Le duc Jean Ir intervint en effet dans trois successions qui concernaient les plus importants seigneurs de Bretagne : celle de Porhoët, celle de Pontchâteau et celle de Dinan.

Comme nous l'avons vu, le règlement de la succession de la maison de Porhoët avait débuté en 1235 par un compromis entre Raoul de Fougères et Guy Mauvoisin, compromis trouvé par le roi de France (Cf. annexe 5- La succession d'Eudes II, vicomte de Porhoët).

L'accord fut définitif en 1238 lorsque Guy Mauvoisin notifia l'accord qu'il avait fait avec Raoul de Fougères. Contre l'abandon de Château-Josselin, de la vicomté et de la terre de Porhoët, il devait recevoir 2500 livres et 200 livres tournois de rente sur les terres normandes de Raoul relevant du roi de France ${ }^{51}$. Ce dernier intervenait donc car il s'occupait alors non seulement de la Bretagne, mais aussi de son duché de Normandie. Après cela, le duc de Bretagne s'intéressa aux terres bretonnes d'Eudes III de Porhoët. En 1239, Raoul III de Fougères, seigneur de Fougères et autres lieux, hérita en mai de son grand père, Eudes III de Porhoët. Il devait donc devenir vicomte de Porhoët, puisque le duc Jean $\mathrm{I}^{\mathrm{er}}$ accepta son hommage pour le fief du Porhoët. Raoul, ennemi de la maison de Dreux, détenait alors la plus importante force militaire du duché. Il s'avéra nécessaire pour le duc de réduire cette puissance. Le duc ne manqua pas d'utiliser deux atouts qu'il détenait. D'une part, Raoul n'était pas le seul héritier d'Eudes de Porhoët, ce dernier ayant eu trois filles dont l'aînée était la mère de Raoul de Fougères. Selon "l'Assise au comte Geoffroy " de 1185, le seigneur de Fougères ne devait obtenir que deux parts de cet héritage ainsi que l'hom-

50. Arch. dép. de Loire-Atlantique, E 151, n 1-6; ms. français 22319, château de Vitré, p. 146-147; Dom MoRICE, Pr., t. I, col. 1037-1040.

51. BnF, fonds français 22330, p. 21; Cartulaire d'Alençon, op. cit., p. 153-154, acte $\mathrm{n}^{\circ} \mathrm{XXXV}$ et Dom Morice, Pr., t. I, col. 907. 
mage des époux de ses tantes. D'autre part, l'une de ses tantes, Aliénor de Porhoët, était membre de la parenté du duc Jean ${ }^{\mathrm{er}}$ puisqu'elle avait épousé le vicomte de Rohan, allié de Pierre Ir ${ }^{\mathrm{er}}$ pendant la guerre civile. Devenue veuve, elle s'était remariée avec l'oncle maternel de Jean I ${ }^{\mathrm{er}}$, Pierre de Thouars, seigneur de Chemillé et de Brissac ${ }^{52}$. Lors de l'hommage d'Angers, Raoul de Fougères avait été contraint d'accepter l'hommage de Pierre de Chemillé pour ce qu'avait sa femme dans le fief de Porhoët. Le duc, en même temps qu'il avait augmenté le patrimoine de son oncle, avait obtenu un allié de poids dans la succession de Porhoët.

En second lieu, en septembre 1239, le duc usa de son droit de seigneur supérieur de la terre de Porhoët et fit les parts de chaque héritier. Raoul qui était exempt du droit de rachat pour la terre de Porhoët, comme le voulait le traité de paix signé à Crépy, eut la paroisse et la forêt de Lannouée avec le château de Josselin. Pierre de Chemillé et la vicomtesse douairière de Rohan, son épouse, devaient avoir La Chèze et La Trinité ainsi que la forêt de Loudéac. Il fallut estimer le patrimoine des Porhoët; furent nommés en tant qu'enquêteurs pour le seigneur de Fougères, Paien d'Ynet et Robert Chesnel, et pour Pierre de Chemillé, Guillaume, fils d'Harsi, fils de Menguy. L'arbitre devait être Guillaume de Montbourcher qui était aussi un adversaire de Raoul de Fougères et un proche du duc ${ }^{53}$. Un an plus tard, le 25 septembre 1240, les deux parties firent un nouvel accord devant le duc de Bretagne. Pierre de Chemillé et son épouse devaient avoir de Raoul de Fougères en supplément de leur part la paroisse de Mohon, à tenir de Raoul en hommage ${ }^{54}$. En même temps, les deux parties s'engagèrent à donner à Jeanne de Porhoët, troisième fille d'Eudes III, une dot à prendre sur les terres de Porhoët ${ }^{55}$. La mort de la veuve d'Eudes de Porhoët permit de revoir encore une fois la succession de Porhoët. Le duc de Bretagne reprit les choses en main. Le 15 avril 1241, à l'abbaye de La Meilleraye, il attesta de l'accord entre Raoul de Fougères d'une part, et ses oncles maternels, Pierre de Chemillé et Olivier de Montauban (époux de Jeanne) de l'autre. Comme le voulait " l'Assise au comte Geoffroy ", Raoul devait avoir deux parts, soit le domaine et le château de Josselin, la forêt de Lannouée et la paroisse de Mohon. Ses oncles devaient recevoir la ville et le château de La Chèze, la ville de La Trinité et la forêt de Loudéac. L'estimation devait être faite par Bonabes de Rougé, Méen de Derval, Jean de Maure et Georges Le Voyer, chevaliers, tous proches du duc de Bretagne ${ }^{56}$. La succession du plus

52. Il était le fils de Guy de Thouars et d'Eustache de Mauléon, dame de Brissac et de Chemillé. Il était donc l'oncle du duc Jean $\mathrm{I}^{\mathrm{er}}$.

53. Dom Morice, Pr., t. I, col. 912-913; Cartulaire du Morbihan, éd. Louis Rosenzweig, Vannes, 1895 (Cart. du Morbihan), p. 221, n 272.

54. BnF, fonds français 22330, p. 25; Arch. dép. d'Ille-et-Vilaine, fonds Hévin, dossier 53, p. 7; Dom Pr., t. I, col. 916; Cartulaire d'Alençon, op. cit., p. 170-171, acte ${ }^{\circ}$ XLVI.

55. BnF, fonds français 22330, p. 26; Dom MoRICE, Pr., t. I, col. 917 ; Cartulaire d'Alençon, op. cit., p. 171-172, acte $\mathrm{n}^{\circ} \mathrm{XLVII}$.

56. BnF, fonds français 22330, p. 27; Arch. dép. d'Ille-et-Vilaine, fonds Hévin, dossier 53, p. 7 ; Dom MoRICE, Pr., t. I, col. 919; Cartulaire d'Alençon, op. cit., p. 172-174, acte ${ }^{\circ}{ }^{\text {XLVIII. }}$ 
important fief de Bretagne ne fut réglée que le 7 novembre 1248 au manoir de La Ville Jagu, résidence de Marguerite, veuve d'Eudes III, entre Raoul de Fougères, Pierre de Chemillé et son épouse, Olivier de Montauban et son épouse. L'accord délimita les possessions de chacun d'entres eux dans le fief de Porhoët : Raoul devait avoir la forêt de Lannouée, la paroisse de Mohon et les deux tiers du douaire de Marguerite, soit les hébergements du Plessis et de La Ville-Jagu. L'autre tiers du douaire devait aller à Pierre de Chemillé et Olivier de Montauban.

Mais un problème se posa. Aliénor de Porhoët et son époux, Pierre de Chemillé, avaient échangé avec le second époux de Marguerite, Caro Bodegat, chevalier du Porhoët, cent livres de rente assises dans la paroisse de Mohon. Il fut alors décidé que Caro devait prêter hommage à Raoul de Fougères tout comme les héritiers du chevalier Henri de Coëtlogon. De plus, Pierre de Chemillé et Olivier de Montauban ne pouvaient pas demander à Raoul de Fougères le parcours de leurs bêtes dans la forêt de Lannouée. Raoul ne pouvait faire de même dans la forêt de Loudéac qui appartenait alors entièrement à Pierre et à Olivier et à leurs femmes ${ }^{57}$. Chacun des héritiers était donc maître chez lui. La division des parts était particulièrement nette. Le duc de Bretagne se trouva le garant de l'accord comme le mentionne un autre acte fait devant la cour de Ploërmel en février $1249^{58}$. Jean ${ }^{\mathrm{er}}$, avec le soutien de son oncle, Pierre de Chemillé, et surtout grâce à cette succession qui s'appuyait sur des règles fixées lors de «l'Assise au comte Geoffroy " de 1185 était parvenu non seulement à disloquer le plus grand fief du duché, la vicomté de Porhoët, mais à accroître la puissance de ses autres alliés, les vicomtes de Rohan, qui devaient hériter en fin de compte d'Aliénor. L'héritier du Porhoët, Raoul de Fougères, pour obtenir son immense héritage, avait été contraint d'abandonner non seulement les fiefs normands des Porhoët, mais aussi une part non négligeable de la vicomté de son grand père. Il devait se contenter de vagues hommages. Jamais, il ne porta le titre prestigieux de vicomte de Porhoët.

Dans le comté de Nantes, deux successions permirent au duc de Bretagne de s'implanter durablement dans ce comté, celle de Pontchâteau et celle de Machecoul. La première succession concerne les Clissons (Cf. annexe 6 - La succession des Clisson).

Olivier de Clisson ne pouvait apprécier que le château de La Bénaste échappât à son lignage car l'héritière de Guillaume de Clisson se maria avec Olivier de Dreux, fils cadet du duc Pierre I $^{\text {er }}$. Outre que son lignage perdait un château majeur, le seigneur de Clisson ne put que constater la

57. Archives départementales du Morbihan (Arch. dép. du Morbihan), fonds de RohanChabot, original, parchemin scellé de cinq sceaux sur double queue; Arch. dép. du Morbihan, 1 E 1471; BnF, fonds français 22330, p. 29; Arch. dép. d'Ille-et-Vilaine, fonds Hévin, dossier 53, p. 12; Médiathèque de Nantes, fonds Bizeul, ${ }^{\circ} 1705$, fr. 1549, fragment de l'original en français et copie partielle du XVII siècle; Dom MoRICE, Pr., t. I, col. 933; Cartulaire du Morbihan, op. cit., p. 223-226, $\mathrm{n}^{\circ} 275$.

58. Dom MoRice, Pr., t. I, col. 940-942. 
création par le duc Jean $\mathrm{I}^{\mathrm{er}}$ d'un puissant fief concurrent du sien au sud de la Loire. Le duc favorisait ainsi son demi-frère cadet. En tant que seigneur de Pontchâteau, Olivier de Clisson aurait ainsi aimé récupérer les revenus de Guérande donnés par le roi de France, Philippe II Auguste, à Eudes de Pontchâteau, son grand-père. Ces revenus étaient retournés au Domaine royal certainement sous Pierre $\mathrm{I}^{\mathrm{er} 59}$. De plus, Olivier de Clisson n'a probablement pas apprécié de voir le duc faire construire le château du Gâvre non loin de son nouveau château de Pontchâteau. Il voyait ainsi se réduire l'héritage provenant de sa mère, la riche Constance de Pontchâteau, dame de Pontchâteau, d'Héric et de Blain, d'autant plus que ses demi-frères cadets, Hervé de Blain et Guillaume de Fresnay, fils de Constance et d'Hervé de Blain, paraissent avoir voulu réclamer plus d'indépendance. Le duc Jean $\mathrm{I}^{\mathrm{er}}$ profita de cette querelle familiale et accepta, le 14 octobre 1252, l'hommage direct des frères utérins d'Olivier de Clisson, certainement très mécontents de la part que leur avait laissée leur aîné. Eudon de Pont et son frère Guillaume de Fresnay, tous deux chevaliers, promirent ainsi leur assistance à Jean Ir alors en conflit contre Olivier de Clisson, à condition que le duc s'efforçât de leur conserver leurs terres dans le fief de Pontchâteau, ou, en cas de confiscation, s'engageât à leur fournir des terres d'égale valeur, sises dans la terre de Blain ou dans le ressort de Guérande ${ }^{60}$. Olivier de Clisson n'était pas de taille à s'opposer au duc de Bretagne. Son château de Clisson fut rasé ${ }^{61}$. Le roi de France intervint, mais donna raison au duc de Bretagne. Olivier de Clisson fut contraint d'abandonner ses terres à son fils, Olivier le Jeune. Ce dernier promit que ni lui, ni ses héritiers ne demanderaient l'autorisation de reconstruire le château de Clisson et qu'ils renonçaient à la restitution des revenus déjà perçus par le duc de Bretagne. Olivier le Jeune devait aussi donner en viager à son père les revenus de la terre de Clisson. Le nouveau seigneur de Clisson promit enfin de payer l'amende énorme de 4000 livres que le duc exigeait de lui ${ }^{62}$.

Jean ${ }^{\text {er }}$ s'attaqua encore à la succession de Machecoul, et cela pour étoffer le domaine de son père qui avait alors perdu la régence du duché et qui n'était plus qu'un seigneur de second ordre. En effet, lorsque Béatrice de Rais, dame de Machecoul, de Luçon, de La Roche-sur-Yon, mourut en 1235, sa fille unique, Jeanne de Thouars, alors mineure, ne reçut pas l'autorisation du duc de Bretagne de succéder à sa mère dans ses fiefs bretons ${ }^{63}$. La terre bretonne de Machecoul fut donnée, vers 1239, à la belle-mère du

59. LA BorDERIE, Arthur de, Recueil d'actes, op. cit., p. 138-139, n 73.

60. Arch. dép. de Loire-Atlantique, E 176, n 12.

61. Arch. dép. de Loire-Atlantique, E 165, n 1 , parchemin, scellé par Jean I I , par Olivier de Clisson, chevalier, par Olivier de Clisson, écuyer, parchemin, en français, nombreuses taches; Dom Morice, Pr., t. I, col. 980-981.

62. Acte de 1262 (Dom Morice, Pr., t. I, col. 987)

63. Le dernier seigneur de Machecoul de la branche aînée de Rais ou de Retz mourut en 1214. Il laissa ses terres de Machecoul, de Saint-Philibert-de-Grandlieu et de Luçon à sa sœur, Béatrix, qui mourut en 1235 (BLANCHARD, René, " Cartulaire des sires de Rays, 1160 1449 ", dans Archives Historiques du Poitou, t. XXVIII et t. XXX, 1898-1900, p. CXXV-CXXVI). 
duc Jean, Marguerite de Montaigu qui avait épousé en 1228 Pierre I ${ }^{\text {er }}$ de Bretagne. En la choisissant, Jean $I^{\text {er }}$ permettait à son père de créer un grand et riche fief sur les Marches du comté nantais, Pierre de Dreux ayant déjà obtenu du roi de France, on ne sait pas par quel moyen, les seigneuries de La Garnache et de Montaigu qui venaient se rajouter à sa terre angevine de Champtoceaux. À la mort de son père en 1250 , Jean ${ }^{\mathrm{er}}$ ne réunit pas Machecoul à son domaine, mais la donna à son demi-frère, Olivier de Dreux ou de Braine, qui porta alors, en 1253, le titre de seigneur de Machecoul et de Saint-Philibert de Grandlieu ${ }^{64}$. La puissance d'Olivier s'accrut lorsque ce dernier épousa Marquise de Souché, fille d'Oliver, seigneur de Souché, et de Pétronille de Clisson, dame de La Bénaste, ce qui n'avait pas été, comme nous l'avons vu, sans provoquer le mécontentement du lignage de Clisson. En mars 1258, une transaction eut lieu devant le roi de France entre Olivier, dit de Machecoul et Jeanne de Thouars, qui était vassale directe du roi et une des plus importantes vassales du roi dans le Poitou. Olivier dut renoncer à la ville et au château de Machecoul et même à la qualification de seigneur de Machecoul. En compensation, il garda tout de même les deux tiers des revenus de la terre de Machecoul ${ }^{65}$. Olivier de DreuxMachecoul était ainsi le grand gagnant de cette transaction. L'accord fut légèrement modifié en 1260, sans doute à la suite du traité de paix entre le duc de Bretagne et Olivier de Clisson, lorsque Jeanne de Thouars mourut et que son héritière directe fut Eustachie, dame de Retz (épouse du poitevin, Girard Chabot). Un nouveau procès eut alors lieu. Olivier conserva toujours Saint-Philibert de Grandlieu, les terres et les droits féodaux sur Machecoul, Bois-de-Cené, Bouin, Saint-Cyr et la petite ville de Bourgneuf ${ }^{66}$. Néanmoins, lui et ses héritiers restèrent ainsi par la grâce du duc de Bretagne les plus importants seigneurs bretons d'Outre-Loire.

Ainsi, en intervenant dans les successions nobiliaires, quitte à devoir combattre pour imposer sa volonté, Jean ${ }^{\mathrm{er}}$ augmentait le nombre de châteaux en sa possession, accroissant ses revenus et imposait aux nobles bretons la constitution de fiefs pour le plus grand profit de membres de sa propre famille. Il montrait ainsi que lui seul autorisait les successions qui n'étaient pas systématiques. En 1275, ce duc obtint le changement de droit de rachat en bail, ce qui lui assurait outre de confortables revenus, le contrôle absolu sur toutes les successions tout en concédant aux nobles le droit de succéder à leurs prédécesseurs. Ces nobles tentèrent bien de se tourner vers le roi de France mais en vain. Les jugements royaux n'étaient

64. Arch. dép. de Loire-Atlantique, H 74, p. 14 vº abbaye de Geneston; LA NicoliERETeIJEIRo, Stéphane de, "Une pierre tombale de l'abbaye de Villeneuve. Olivier de Machecoul ", dans Bulletin de la Société Archéologique de Nantes (BSAN), t. 1, 1859-1861, p. 258-275; VALHEN, Guillaume, "L'origine de la seconde famille de Machecoul ", dans BSAN, t. LXXV, 1935, p. 114-135.

65. BlancharD, René, "Cartulaire des sires... ", loc. cit., p. cXXXII et p. LXXXIV.

66. En septembre 1260, Girard Chabot et son épouse furent investis du château de Machecoul et d'une partie de la seigneurie de Machecoul (BLANCHARD, René, Cartulaire des sires..., loc. cit., p. LXXXV, voir aussi les documents, ibid., n CCXXXIV, LXIV, LXV, CXVI et CXCIII). 
que des compromis toujours en faveur du duc, de ses alliés et parents (Cf. annexe 7 - Généalogie des Rais ou de Rays).

À partir de 1275, d'autres successions confirment que le duc de Bretagne était devenu le maître incontesté de son duché. Tout d'abord, la succession d'Henri ${ }^{\text {er }}$ d'Avaugour fut une aubaine pour le duc de Bretagne ${ }^{67}$. Cette succession débuta en 1281. À la mort de son grand-père, Henri II d'Avaugour, seigneur de Mayenne (dans le Maine) et de L'Aigle (en Normandie), refusa de prêter hommage au duc de Bretagne, Jean I ${ }^{\text {er }}$, pour tout l'héritage breton de son grand-père, Henri I ${ }^{\text {er }}$, soit les terres de Goëlo et de Quintin, tant qu'il ne recevrait pas les biens issus de sa mère, c'est-à-dire la seigneurie de Dinan-nord. En effet, en 1264, son père, Alain, alors qu'Henri était mineur, avait vendu à Pierre de Bretagne, fils cadet de Jean $\mathrm{I}^{\mathrm{er}}$, tous ses biens en Bretagne et même ceux de son épouse, Clémence de Beaufort, dame de Dinan-nord. Pierre de Bretagne les revendit peu après à son père ${ }^{68}$. Henri I ${ }^{\text {er }}$ d'Avaugour, dès 1265, n'accepta pas cette transaction et attaqua la vente devant le roi de France, prétextant de la folie, de la prodigalité et de l'incompétence à gouverner de son fils ${ }^{69}$ (Cf. annexe 8 - La succession d'Henri I ${ }^{\text {er }}$ d'Avaugour). Le roi trouva une nouvelle fois un compromis. Henri $\mathrm{I}^{\mathrm{er}}$ d'Avaugour obtint du roi d'abord la tutelle de son petit-fils, Henriot (le futur Henri II), ne réclama pas Dinan-sud et le château de Léhon, qui appartenaient en propre à Alain, mais exigea Dinan-nord et surtout l'hommage du duc, alors seigneur de Dinan-sud et donc vassal du seigneur de Dinannord. Le duc refusa à la fois de prêter hommage et de rendre Dinan-nord. L'affaire fut une nouvelle fois portée devant le roi de France ${ }^{70}$. Le duc céda, le 26 octobre 1267, et promit de rendre à Henriot, à sa majorité, c'est-àdire dans cinq ans, les biens de sa mère. En attendant, Jean ${ }^{\text {er }}$ devait lui verser une rente de 300 livres bretonnes ${ }^{71}$. Malgré tout, il semblerait qu'à la mort d'Henri I ${ }^{\text {er }}$, rien n'avait été rendu. Le roi de France, Philippe III le Hardi, intervint pour désamorcer une situation explosive, risquant d'embraser la Bretagne et le nord-ouest du royaume de France. En juillet 1281, un accord fut signé devant lui. Pour récupérer Dinan, Henri II se devait de rembourser les sommes versées par le duc de Bretagne pour l'acquisition de Dinan. Henri II procéda alors à un montage financier savant. Il tenta de donner comme caution à ce remboursement sa terre de Passy-sur-Marne ${ }^{72}$. Mais cela ne fonctionna pas car en novembre de la même année, il fut contraint d'abandonner la terre de Passy et le péage de Nogent-sur-Marne

67. Voir l'arbre généalogique des Eudonides en fin d'article.

68. Dom Morice, Pr., t. I, col. 991.

69. Registres dits Olim (1254-1319) ou registres des arrêts rendus par la Cour du roi..., Paris, 1839-1848, tome : 1254-1273, p. 624-625.

70. Olim, op. cit., t. I, 670-671.

71. Angot, Alphonse, Généalogies féodales mayennaises du XI au XIII siècle, Laval, 1942, p. 621-622; Dom Morice, Pr., t. I, col. 1015 (avec le vidimus du roi de France, de Paris, daté de décembre 1268)

72. Acte de Philippe III le Hardi, roi de France (Dom MoricE, Pr., t. I, col. 1052-1053, Église de Tours) 
à son beau-frère, Guy VII de Laval, afin de récupérer le fief de L'Aigle. En effet, il avait auparavant opéré un échange avec à Guillaume de Beaumontsur-Oise, L'Aigle contre Passy. Lorsque Guillaume de Beaumont mourut, la terre de L'Aigle tomba entre les mains de son petit-fils, Guillaume de Laval, fils cadet de Guy de Laval. Ce dernier agissait donc dans cette transaction au nom de son fils ${ }^{73}$.

Pour remplacer Passy-sur-Marne, Henri d'Avaugour voulut donner au duc la terre de L'Aigle alors récupérée. Mais il dut traiter avec son oncle, Geoffroy d'Avaugour qui réclamait très certainement L'Aigle comme sa part dans l'héritage de son père, Henri I ${ }^{\text {er }}$ d'Avaugour. Devant le roi de France, en 1282, à Paris, Geoffroy renonça à ses droits sur la terre de L'Aigle et la maison qui fut au comte de Macon (frère de Pierre de Dreux, duc de Bretagne) contre cent livres de rente transmissibles, à prendre à l'abbaye de Beauport à la Saint-Michel ${ }^{74}$. En 1283, l'accord définitif eut enfin lieu entre le duc et Henri II d'Avaugour : les terres de L'Aigle et de Margon (cette dernière dans le Perche, dot de son épouse) furent données au duc de Bretagne. Henri II laissa au duc comme otages, à Carhaix, cité ducale, ses principaux vassaux : le seigneur de Quintin, le vicomte de Tonquédec et le seigneur de La Hunaudaye. Il constitua aussi en garantie la moitié du " champ et de la ville de Dinan ", le château de Léhon et 2000 livres. Le duc devait conserver le reste de Dinan en viager et l'autre moitié du marché de Dinan contre 500 livres de rente. L'acte mentionne encore qu'Henri II devait renoncer à réédifier le château de Châtelaudren dans le Goëlo et à réclamer la restitution des impôts levés à Dinan ${ }^{75}$. Enfin, il se devait de supplier le roi de France de recevoir l'hommage du duc de Bretagne pour la terre de L'Aigle. Deux ans plus tard, le duc Jean Irr mourut et Henri II put récupérer sa part de Dinan et sa terre de L'Aigle. Mais force est de constater que là encore un grand seigneur breton n'avait pas reçu l'appui du roi de France.

\section{Les interventions du duc Jean II}

L'affaire d'Avaugour est la dernière succession de la noblesse bretonne à laquelle le roi de France participa directement. Pendant tout le règne de Jean II (1286-1305), tous les conflits de succession se réglaient devant sa cour de Ploërmel. Durant une grande partie du règne du roi Philippe le Bel, la faveur royale était particulièrement importante à l'égard de Jean II. En 1296, le roi l'informa qu'il cassait tous les appels des Bretons portés devant sa cour ${ }^{76}$. En février 1297, il accorda au " comte de Bretagne " et à

73. Broussillon, Bertrand de, op. cit. p. 44 et Angot, Alphonse, Généalogies féodales... op. cit., p. 623 .

74. BnF, ms. français 22325, p. 860; Dom MORICE, Pr., t. I, col. 1063.

75. Dom Morice, Pr., t. I, col. 1066-1067; Arch. nat., J 241 ${ }^{\mathrm{A}}, \mathrm{n}^{\circ} 21$.

76. 1296, février, à Paris, Lettres patentes de Philippe le Bel portant règlement pour le cas dans lesquels Jean, comte de Bretagne et ses sujets pourront être ajournés devant les officiers du roi. (Arch. nat., J 241 B, n ${ }^{\circ} 31^{1}$; Arch. nat., X 8, $\mathrm{f}^{\circ} 11$, ordonnance antique, $f^{\circ} 127$; Dom Morice, pr., t. I, col. 1122, château de Nantes). 
ses héritiers le droit d'être ajournés devant lui ou ses gens seulement en cas de déni de justice ou de mauvais jugement ${ }^{77}$. En septembre de la même année, il éleva Jean II au rang de duc et pair du royaume ${ }^{78}$ et lui donna la châtellenie normande de Thorigny-sur-Vire (dans la vicomté de Bayeux) d'une valeur de 1000 livres de rente ${ }^{79}$. Ainsi, devant la Cour ducale, passa une série d'affaires de succession dans lesquelles le roi de France n'agit aucunement.

En 1285, il fallut régler la succession de Mahaut de Montfort, veuve de Josselin de Rohan, seigneur de La Roche ${ }^{80}$. Mahaut ayant donné à son époux le tiers de sa terre de Montfort, cette part passa au fils de Josselin, Alain de La Roche qui le donna ou le vendit, on ne sait pas trop, au seigneur de Lohéac. Ce dernier ne la conserva pas en entier car il donna la moitié de ce tiers à Alain de Montauban. L'héritier de Mahaud, Raoul, seigneur de Montfort et de Gaël, qui voulait reconstituer l'ensemble du fief de Montfort, fut contraint de transiger. Devant le duc, il renonça en faveur d'Alain de Montauban à son château de Boutavant contre ce que tenait Alain dans la paroisse de La Chapelle ${ }^{81}$ (Cf. annexe 9 - La succession des Montfort).

En 1286, Olivier, seigneur de Montauban, et sa sœeur Aliette, firent un accord devant la cour ducale sur la part d'héritage d'Aliette ${ }^{82}$.

En 1291 eut lieu l'affaire de Guillaume de Montbourcher qui réclamait à son seigneur, le comte de La Marche, époux de la dame de Fougères, la restitution des biens de son père à Sens et à Vieux-Vy-sur-Couesnon ${ }^{83}$.

77. Arch. dép. de Loire-Atlantique, E $110, \mathrm{n}^{\circ} 3$; Bibl. nat., ms. français $5512, \mathrm{f}^{\circ} 6$.

78. Le 7 septembre 1297, à Courtrai, Lettres patentes de Philippe IV le Bel, roi de France, érigeant en duché-pairie la Bretagne et imposant en retour l'hommage au roi du duc Jean II et à ses successeurs les devoirs de faire hommage à la Couronne de France (Arch. dép. de Loire-Atlantique, E 103, n 4, original ; Arch. dép. de Loire-Atlantique, E 113, cartulaire, $\mathrm{f}^{\circ}$ 12, copie; Dom MoRICE, pr., t. I, col. 1122-1123, château de Nantes).

79. Arch. dép. de Loire-Atlantique, E $103, n^{\circ} 5$, original en latin et copie en français 103 , $\mathrm{n}^{\circ} 6$.

80. Voir la généalogie de la maison de Montfort en fin d'article.

81. Dom Morice, pr., t. I, col. 1074-1075, copie de du Paz.

82. En avril 1286, à Ploërmel, accord fait devant la cour ducale entre Olivier, seigneur de Montauban, et sa sœur Aliette qui réclamait sa part d'héritage, soit 100 livres de rente sur Menéac, Ceymor, Beier et Ploec. Il fut décidé qu'elle aurait 70 livres de rente sur les 100 livres et 20 livres d'Alain de Montauban, chevalier, et dame Anne de Montauban (Dom Morice, Pr., t. I, col. 1078-1079, archives de Guéméné).

83. Le 12 juin 1291, devant la cour ducale de Rennes, sentence arbitrale rendue par Geoffroy, seigneur de Châteaubriant, chevalier, entre maître Guillaume Lolier, clerc, sénéchal et procureur de noble homme Hugues le Brun, comte de La Marche et d'Angoulême, seigneur de Fougères d'une part, et Guillaume de Montbourcher, écuyer, de l'autre, au sujet de créances réciproques héritées. Le comte de La Marche réclamait 900 livres restant d'une créance de 1400 livres due par Geoffroy de Montbourcher, père de Guillaume, à Raoul de Fougères, pour composition et paix venant d'un différend entre eux. Comme un grand charroi de vins avait versé dans le chemin de Amont, le comte de La Marche demandait donc les 900 livres comme héritier de Raoul de Fougères. Guillaume de Montbourcher réclamait la seigneurie, la justice et les domaines des paroisses de Sens et de Vieux-Vysur-Couesnon par droit d'héritage. Le comte de La Marche disait qu'elles devaient rester en sa main car elles étaient issues de la composition de Geoffroy de Montbourcher. Le 
En 1298 se termina définitivement la succession des vicomtes de Léon sans que le roi de France intervienne. Prigent de Coëtmen, vicomte de Tonquédec, époux d'Anne de Léon, une des héritières du dernier vicomte de Léon, réclama au duc de Bretagne, 3000 livres et les obtint ${ }^{84}$. Un autre des héritiers de la vicomté, Rolland de Dinan-Montafilant, cité comme noble homme, reçut 2000 livres sur quatre ans ${ }^{85}$ (Cf. annexe 10 - La succession d'Hervé III, vicomte de Léon).

En 1299 eut encore lieu la succession d'Alain de Rohan ${ }^{86}$ (Cf. annexe 11 - La succession d'Alain VI, vicomte de Rohan). En effet, Alain VI, vicomte de Rohan, qui régnait sur sa vicomté depuis 1251, avait donné à son fils aîné et héritier, Alain, le tiers de ses terres en avance sur son héritage. Mais Alain mourut en 1299 sans descendance. Le vicomte de Rohan dut alors payer au duc le droit de rachat, soit 1300 livres, qui devait être garanti par ses principaux vassaux. Il dut aussi reconnaître que le duc de Bretagne possédait dans sa terre les droits de ligence, de rachat et de vente à lever sur les juveigneurs de sa vicomté et sur toutes ses terres de Bretagne ${ }^{87}$. Alain VI perdit donc une part importante de son autorité dans ses fiefs. Il subit aussi d'autres déboires en matière successorale. En 1301, il perdit le procès qu'il avait devant la Cour ducale avec sa nièce, Isabelle, fille de sa sœur, Philippe, et épouse d'Olivier de Tinténiac. Il dut lui abandonner une rente de 45 livres $^{88}$. La mort de son second fils et héritier, Geoffroy, lui coûta aussi très cher. Enfin, il résista longtemps aux demandes de la veuve de son fils, Catherine de Clisson, qui lui réclamait son douaire, soit le tiers de la vicomté de Rohan et de toutes les terres que possédait la maison de Rohan dans la vicomté de Porhoët, soit un total de 500 livres de rentes. Elle n'obtint que 100 livres de rente, sans doute parce qu'elle n'était pas parvenue à devenir vicomtesse de Rohan ${ }^{89}$.

À une autre époque, la noblesse bretonne se serait tournée vers le roi de France. Ce n'était plus le cas du fait des privilèges que le duc Jean II avait obtenus du roi de France. Il est à remarquer que les nobles essayèrent de trouver en interne des arrangements afin d'éviter les successions difficiles,

seigneur de Châteaubriant décida alors que le comte de La Marche paierait à Guillaume de Montbourcher 160 livres de monnaie courante. Guillaume de Montbourcher demeura homme lige du comte de La Marche (Cartulaire d'Alençon, op. cit., p. 115-117, $\mathrm{n}^{\circ} \mathrm{XIII}$ ).

84. Arch. dép. de Loire-Atlantique, E 24, n 1, original. A.E., t. VI, p. 211, n CLXX.

85. 1298, sentence arbitrale des chevaliers Robin Raguenel, Jean de Maure et Guillaume Hay, proche conseiller du duc, entre le duc Jean II et Rolland de Dinan, chevalier, au sujet de la vicomté de Léon. Rolland de Dinan recevra 2000 livres de monnaie courante. Rolland devra assigner au duc 700 livres de rente pour la dette de Guyomarc'h de Lanneen envers le duc (Dom Morice, Pr., t. I, col. 1127-1128).

86. Voir l'article "Alain VI, vicomte de Rohan... ", dans Bulletin Polymathique du Morbihan.

87. Dom Morice, Pr., t. I, col. 1135-1136.

88. Dom Morice, Pr., t. I, col. 1138.

89. Dom Morice, Pr., t. I, col. 1181-1182, "pris sur l'original au château de Blain "; BnF, fonds français 22325, "titres de Blain ", p. 834; Médiathèque de Nantes, fonds Bizeul, $\mathrm{n}^{\circ} 1702$, fr. 1546 . 
sans doute trop ruineuses financièrement et politiquement, car faire intervenir l'arbitrage ducal signifiait accepter une perte de pouvoir et le risque de se retrouver débouté, surtout si son adversaire était un proche de la maison ducale comme le comte de La Marche.

\section{Le retour de l'intervention royale (1302-1341)}

À partir de la bataille de Courtrai (1302) qui fut un véritable désastre pour la monarchie capétienne, la situation politique connut une nouvelle mutation et permit à la noblesse bretonne de s'adresser au roi de France avec beaucoup plus d'efficacité. Le roi intervint de nouveau dans les règlements des successions nobiliaires bretonnes, méthode simple et imparable pour montrer toute son autorité au duc de Bretagne. Toutefois tous les rois de France n'eurent pas la même politique envers les ducs de Bretagne, les rois de France furent plus exigeants envers leurs grands vassaux. Si Philippe le Bel et Philippe le Long furent très durs envers les ducs, les rois Charles IV le Bel (1322-1328) et Philippe VI de Valois furent plus favorable, surtout envers le dernier duc de la maison de Dreux, Jean III, et eurent, en Bretagne, une politique plus souple.

\section{Un interventionnisme royal autoritaire}

Tout d'abord, Philippe IV le Bel changea de comportement à l'égard du duc Jean II. Après l'avoir couvert de biens et de privilèges, surtout vers 1296 , certainement pour obtenir son soutien lors de la reprise de la guerre avec l'Angleterre, le roi de France fut plus exigeant après la défaire de Courtrai. Il lui fallait, en effet, mobiliser toutes les énergies afin d'empêcher la propagation de la rébellion flamande. Il semblerait que Jean II, comme d'autres Grands du royaume, n'ait pas été à la hauteur des espoirs du roi. Ce duc aurait même pensé à fuir, en 1304, lors de la bataille décisive de Mons-en-Pévèle. Heureusement pour lui, Jean II ne subit pas le même sort que son cousin, le comte de La Marche, qui, lui, perdit tous ses biens, car il mourut accidentellement, à Lyon, en 1305, lors du couronnement du pape Clément V. Les rapports du roi avec le nouveau duc, Arthur II, furent meilleurs. La seconde épouse du duc, Yolande de Dreux, était alors une protégée du roi. En outre, Arthur II avait, dans le royaume, d'autres intérêts particulièrement importants : son grand fief du Perche, le comté de Montfort-L'Amaury qu'il avait racheté pour sa femme, et surtout la vicomté de Limoges plus ou moins achetée par son père lors de son premier mariage avec Marie, héritière de cette vicomté.

Le retour du roi de France dans les règlements des successions nobiliaires en Bretagne fut particulièrement visible dans l'affaire de la succession des Lusignan, affaire qui dura de 1302 à $1312^{90}$. Philippe le Bel profita de cette succession pour s'emparer des biens des Lusignan, non seulement

90. Voir l'arbre généalogique de la maison de Lusignan. 
dans son royaume (les comtés de la Marche et d'Angoulême, la terre de Lusignan, une des plus importantes du Poitou), mais aussi dans le duché de Bretagne, c'est-à-dire les terres de Fougères et de Porhoët qui étaient les plus importantes de la péninsule. Le souverain capétien ne fit donc pas de distinction entre les biens des Lusignan relevant directement de lui (les fiefs d'Angoulême, de la Marche et des Lusignan) et les terres relevant directement de son vassal, le duc de Bretagne (les fiefs de Porhoët et de Fougères). En s'emparant de tous ces biens, le roi de France refusait donc de considérer les droits d'un de ses plus puissants feudataires. L'affaire commença donc en 1302, justement après le désastre de Courtrai (Cf. annexe 12 - La succession des Lusignan).

Hugues XIII, comte de La Marche et d'Angoulême, avant de partir vers la Flandre, en août 1302, écrivit un codicille à son testament et fit de Geoffroy de Lusignan, seigneur de Châteauneuf-sur-Charente et de Jarnac, son légataire universel, déshéritant ainsi son frère cadet, Guy. Pourtant, le roi de France, Philippe IV le Bel, ne reconnut pas ce legs qui dérogeait aux règles de succession de la maison de Lusignan et le $1^{\text {er }}$ juillet 1304 , Guy de Lusignan hérita tout de même de tous les biens de son frère aîné, soit les comtés de La Marche et d'Angoulême, ainsi que les terres poitevines et bretonnes des Lusignan. Guy s'occupa alors de sa propre succession. N'ayant pas d'enfant, il désigna son neveu, Renaud du Pons, comme son héritier universel. La mère de ce dernier, Yolande de Lusignan, en cas de décès sans enfant de Guy, devait bénéficier de la jouissance en viager des biens familiaux en tant que sœur aînée. La veuve de Hugues XIII, Béatrix de Bourgogne, qui n'était rien moins que la sœur du duc de Bourgogne, de Marguerite de Bourgogne (l'épouse du futur Louis X le Hutin) et de Jeanne de Bourgogne (l'épouse du futur Philippe VI de Valois), obtint tous les acquis de son mari ainsi que la terre de Bouteville et 3000 livres de rente sur la terre de Fougères. Toutefois, la décision du roi de France fut mal récompensée : il semblerait que Guy fit partie de ses grands seigneurs qui complotèrent, en 1304, à Mons-en-Pévèle. En juin 1305, Guy s'allia même avec son cousin le roi d'Angleterre. Le roi de France s'empressa de faire la paix avec son homologue anglais quelques mois plus tard car les terres de Guy auraient permis aux forces anglaises de débarquer au nord de la Bretagne et en "Charente " et de contrôler une grande partie de la façade atlantique. Malgré tout, Philippe le Bel, prudent, sans doute pour ne pas froisser la susceptibilité de ses grands vassaux, attendit la mort de Guy pour confisquer les biens des Lusignan. Il n'avait guère le choix car les héritiers de Guy étaient soit très proches du roi d'Angleterre, soit de sexe féminin, et donc étaient inaptes à commander les importantes forces militaires issues des immenses possessions des Lusignan, si vitales pour le roi de France. En effet, l'héritier en ligne masculine des Lusignan était le puissant seigneur anglais Aymar de Valence, comte de Pembroke ${ }^{91}$. Les

91. Voir la biographie de ce haut personnage de la cour anglaise dans PHILIPPS, J. R. S., Aymer de Valence, earl of Pembroke, 1307-1324, Oxford, 1972. 
sœurs d'Hugues XIII et de Guy étaient encore vivantes et devaient aussi avoir leurs parts d'héritage.

L'aînée, Yolande, née en 1257, était alors veuve de Renaud du Pons et peut-être aussi de Robert de Mareuil. Elle avait un fils nommé Renaud du Pons, alors sans doute mineur, qui devait hériter de son oncle. Jeanne, morte en 1321, était veuve de Pierre de Joinville, seigneur de Vaucouleurs (décédé en 1292), frère de l'historien de saint Louis. Peut-être fut-elle aussi l'épouse de Bernard Ezy, sire d'Albret et vicomte de Tartas. Elle eut trois filles : Béatrix et Mahaut de Joinville, qui furent toutes deux religieuses au couvent d'Acornbury en Irlande, et Jeanne de Joinville qui épousa Roger Mortimer, lord Meath en Irlande et de Wigmore en Angleterre ${ }^{92}$ et devint ainsi la mère du très célèbre Roger Mortimer, comte de March, amant de la reine Isabelle d'Angleterre. Marie de Lusignan, la troisième sœur, était depuis 1288 l'épouse d'un des membres du lignage ducal de Bourgogne, Étienne, comte de Sancerre (mort en 1306). Elle était alors sans enfant. Enfin, Isabelle était religieuse à l'abbaye royale de Fontevrault; elle était encore vivante en 1304. Elle aurait épousé Jean de Vécy, un seigneur anglais, mort vers 1290 .

Le roi de France négocia donc avec ces héritiers. Marie de Lusignan, comtesse de Sancerre, obtint le $1^{\mathrm{er}}$ janvier 1309, à Paris, comme il est indiqué dans l'acte, en raison de la compassion que le roi eut pour elle et en considération de l'affection qu'avait ce même roi pour feu Étienne, comte de Sancerre, époux de la comtesse, mort à son service, deux rentes, l'une de 600 livres sur le Trésor et la sénéchaussée de Poitou et l'autre de 200 livres sur les comtés en litige. Elle devait aussi recevoir 1000 livres de rente à prendre sur les terres et un château ou une maison forte avec haute et basse justice, le tout à tenir en fief du roi. Elle devait enfin avoir 10000 livres tournois à payer en une seule fois ainsi que la maison qu'Hugues le Brun possédait dans le quartier Saint-Marcel, à Paris. En contrepartie, Marie de Lusignan renonça à tous ses droits sur les comtés de La Marche et d'Angoulême et sur la terre de Fougères ${ }^{93}$. En février 1309, toujours dans la capitale du royaume, le roi s'occupa du cas d'Aymar de Valence, comte de Pembroke, lord de Wexford et seigneur de Montignac-Charente. Des lettres datées du 17 février 1309 furent publiées. Dans ces lettres, Aymar notifiait l'accord conclu entre lui et les gens du roi, en vertu duquel il renonçait à tous ses droits sur les comtés de La Marche et d'Angoulême et sur la terre de Fougères, moyennant une rente de 1000 livres à tenir du roi en fief à l'hommage-lige, rente qui serait assise sur lesdits territoires, et, en atten-

92. Voir FRAME, Robin, The English Lordship in Ireland, 1318-1361, Oxford, 1982. Référence fournie par le professeur Michael JonES.

93. Arch. nat., JJ 40, f 45 v.-46 v. Registres du Trésor de Chartes, t. I : règne de Philippe le Bel. Inventaire analytique par Jean GLENISSON et Jean GUEROUT, sous la direction de Robert FAWTIER, Paris, 1958. n 94 et Registres du Trésor des Chartes, t. II, règnes des fils de Philippe le Bel. Deuxième partie : règnes de Louis X le Hutin et de Philippe V le Long. Inventaire analytique, établi par Jean GUEROUT, sous la direction de Robert FAWTIER, Paris, 1966, p. 70, $\mathrm{n}^{\circ} 436$ 
dant que l'assiette de la rente fût faite, une rente de 1600 livres tournois devait lui être versée, assignée hors de ces territoires ${ }^{94}$.

Le mois suivant, en mars 1309, toujours à Paris, fut réglé le cas de Yolande de La Marche, dame de Pons. Yolande réclamait les comtés de La Marche et d'Angoulême et la baronnie de Lusignan avec toutes leurs dépendances, en tant qu'héritière légitime, au titre de sœur aînée de Guy, comte de La Marche, alors décédé. Le roi lui accorda donc l'usufruit de cet héritage. Toutefois, le roi conserva pour lui les châtellenies de Merpins et Cognac ${ }^{95}$. Yolande n'avait à prêter aucun hommage et ne recevait aussi aucun hommage du roi de France. Elle pouvait alors s'intituler " Iolande de Lusignan, comtesse de La Marche et d'Angoulême, dame de Fougères ${ }^{96}$ ". Si Yolande obtint aussi la terre de Fougères, sa belle-sœur, Béatrix de Bourgogne, veuve d'Hugues de La Marche, avait celle de Porhoët comme le montre un acte fait à Maubuisson en mai 1311 et confirmant un autre acte daté du $1^{\mathrm{er}}$ décembre 1310. Ce document mentionne en effet que Yolande, en tant que dame et propriétaire de Fougères, de Porhoët et des autres terres qui furent à ses frères Hugues et Guy de La Marche, se devait de continuer de payer les 3000 livres de rente annuelle pour le douaire de Béatrix. Cet acte révèle aussi que ce fut le duc de Bretagne qui avait autrefois assis cette rente sur la terre de Porhoët et sur d'autres lieux dont Béatrice avait pris possession et qui correspondait au tiers des revenus de son ancien mari, revenus auxquels Béatrix avait droit, à titre de douaire ${ }^{97}$.

Pour ce qui est des autres héritiers, ils reçurent d'importantes rentes et terres leur permettant de renoncer facilement à leurs prétentions. Ainsi, Jeanne de Lusignan, dame de Joinville, reçut les châtellenies de Couhé en Poitou et de Peyrat dans le comté de La Marche, ainsi qu'une somme de 1000 livres ${ }^{98}$. Les autres descendants de la reine Isabelle d'Angleterre, comtesse d'Angoulême, Hélie Rudel et Amaury III de Craon, devaient avoir chacun 1000 livres et un château ${ }^{99}$.

Ainsi, il est possible de remarquer que le roi de France avait procédé par étape. Il ne voulait pas se brouiller avec les grands seigneurs de sa cour, ni avec le duc Arthur II de Bretagne qui lui était particulière-

94. Arch. nat., J 374, $\mathrm{n}^{\circ} 6$ et 6 bis; Arch. nat., JJ 38, f ${ }^{\circ} 62-62$ v, $\mathrm{n}^{\circ} 128$; Registres du Trésor de Chartes, t. I : règne de Philippe le Bel, op. cit, $\mathrm{n}^{\circ}$ 470, p. 76.

95. Arch. nat., J 407, n 12 et 13; Arch. nat., J 374, n 8 et $8^{\text {bis }}$; Arch. nat., JJ 40, f ${ }^{\circ} 86-67$ v.; Registres du Trésor de Chartes, t. I : règne de Philippe le Bel, op. cit., ${ }^{\circ} 166$; Registres du Trésor des Chartes, t. II, règnes des fils de Philippe le Bel. Deuxième partie : règnes de Louis X le Hutin et de Philippe Vle Long, op. cit., p. 70, ${ }^{\circ} 436$.

96. Arch. nat., J 374, n 7; Arch. nat., JJ 40, f 91 v.-92; Registres du Trésor de Chartes, t. I : règne de Philippe le Bel, op. cit., $\mathrm{n}^{\circ} 176$; Registres du Trésor des Chartes, t. II, règnes des fils de Philippe le Bel. Deuxième partie : règnes de Louis X le Hutin et de Philippe V le Long, op. cit., p. 86, n 519

97. Arch. nat., JJ 46, f ${ }^{\circ} 6$ v-7 v., $\mathrm{n}^{\circ} 7$; Registres du Trésor de Chartes, t. I : règne de Philippe le Bel, op. cit., $\mathrm{n}^{\circ} 1281$, p. 241.

98. Arch. nat., J 270, n 15.

99. Burfas, Jean, Géographie historique du comté d'Angoulême, 1308-1331, thèse, Angoulême, 1957, p. 52. 
ment attaché. Il renonça donc temporairement aux terres bretonnes des Lusignan. De surcroît, en devenant seigneur de Fougères et de Porhoët, il se serait mis dans une position difficile car il aurait été contraint de prêter hommage lige à un de ses plus importants vassaux. Toutefois, si Philippe le Bel semble avoir apprécié Arthur II, il est certain qu'il n'aimait pas Jean III, fils aîné d'Arthur II et de Marie de Limoges, qui, lui, détestait cordialement sa belle-mère, Yolande de Dreux. Dès l'annonce du décès de Yolande de Lusignan, le 12 octobre 1314, le roi ordonna à son chevalier, Hugues de La Celle, de saisir les terres de Fougères et de Château-Josselin dans le Porhoët ${ }^{100}$, comme si le roi avait craint que le duc Jean III ne s'en empare.

\section{Le duc Jean III autorisé par le roi à intervenir}

La mort, peu après, de Philippe le Bel fournit quelques répits à Jean III car il était le beau-fils de Charles de Valois, l'oncle et le principal conseiller du nouveau roi Louis X le Hutin, qui était devenu automatiquement, à la mort de son père, seigneur de Fougères et de Porhoët. Le roi accorda au duc de Bretagne ce qu'il voulait : le duché de Bretagne retrouva ses privilèges judiciaires ${ }^{101}$; le roi s'attaqua à l'héritage de Yolande de Dreux sur l'affaire de son comté de Montfort-l'Amaury ${ }^{102}$ et enfin, Louis X le Hutin renonça à recevoir les hommages de Porhoët et de Fougères en donnant en accroissement d'apanage, le 11 mai 1316, à son frère, Charles de France, alors comte de La Marche, ces terres bretonnes ${ }^{103}$.

Toutefois, le règne de Louis X ne dura pas. Philippe V le Long lui succéda en novembre 1316. Ce roi mena la vie dure au duc Jean III car il était un proche de Yolande de Dreux. Le roi utilisa souvent ses pouvoirs judiciaires et son parlement afin de contraindre le duc de Bretagne. Comme ses prédécesseurs, il utilisa les appels bretons afin d'intervenir dans les affaires de succession bretonnes auxquelles était mêlé Jean III. Ainsi, le 9 mars 1321, le duc fut convoqué devant le parlement de Paris (aux Grands Jours de Normandie) pour répondre à la plainte de Pierre d'Acigné, tuteur des enfants de Brient de Châteaugiron. Pierre s'était plaint au roi de ce que ses pupilles avaient été déshérités par le duc de Bretagne ${ }^{104}$. En effet, en 1317, Brient de Châteaugiron et son épouse avaient renoncé à leur châtellenie et à leur baronnie de Châteaugiron contre le manoir ducal de Damany dans le

100. Dom Morice, Pr., t. I, col. 1251-1252.

101. Arch. nat., X 8, $\mathrm{f}^{\circ} 13$. Ce privilège fut renouvelé les 2 mars et 2 mai 1316 (Arch. nat., $\mathrm{X} 8, \mathrm{f}^{\circ} 14$; Bibl. nat., ms. français $5512, \mathrm{f}^{\circ} 30-32$ ).

102. Arch. nat., JJ 50, f 90 v-92, n 140; Registres du Trésor des Chartes, t. II : règnes des fils de Philippe le Bel. Première partie : règnes de Louis X le Hutin et de Philippe Vle Long. Inventaire analytique par Jean GUEROUT, sous la direction de Robert FAWTIER, Paris, 1966, $\mathrm{n}^{\circ} 42$, p. $8-9$.

103. Dom Morice, pr., t. I, col. 1363; Cartulaires du Morbihan, op. cit., p. 409-410, $\mathrm{n}^{\circ} 494$. 104. BouTARIC, Edgar, Actes du Parlement de Paris, première série : de l'an 1254 à l'an 1328, tome II : 1299-1328, Paris, 1867, p. 349, n 6313, d'après Greffe, t. I, f ${ }^{\circ} 78$ v. 
Léon ${ }^{105}$. Pierre d'Acigné eut gain de cause et Jean III dut restituer les fiefs de Châteaugiron et d'Amanlis aux enfants de Brient, sans doute que le manoir et les terres ducales qui en dépendaient n'avaient pas la même valeur que le fief de Châteaugiron ${ }^{106}$.

La mort de Philippe V le Long fut une délivrance pour Jean III. La situation du duc de Bretagne s'améliora dès lors et cela jusqu'à la fin de son règne en 1341. La raison en est très simple : le pouvoir appartenait alors aux Valois, proches parents de Jean III. Charles de Valois, le beau-père de Jean III, était le principal conseiller de son neveu, le roi Charles IV. Le successeur de ce dernier, Philippe VI de Valois, roi de France, était le beaufrère de Jean III et aussi son cousin germain par alliance. Son principal conseiller, Robert d'Artois, était un autre cousin germain de Jean III. Le duc de Bretagne récupéra donc ses privilèges judiciaires et parvint à s'immiscer dans les affaires de succession de la noblesse de son duché, dont certains membres étaient par ailleurs vassaux directs du roi pour d'autres fiefs. Le souverain breton intervint dans le règlement de la succession d'Hervé de Léon, le plus important vassal du duc dans les évêchés de Vannes, de Léon et de Cornouaille. Le 8 juin 1323, devant la cour ducale de à Lesneven, Hervé de Léon, chevalier, seigneur de Noyon-sur-Andelle, " noble homme et puissant ", fit un accord avec Étienne Gauvin de La Roche-Moisan, chevalier, touchant la succession de Guillaume de La Roche-Moisan. Hervé réclama sa part comme héritier de sa tante paternelle, Amice. Étienne Gauvin donna pour apurer leur différend non seulement le manoir de La Roche-Moisan, celui de Botbleiz, la ville de Pont-Scorff, sa partie de l'île de Groix, ce qu'il avait dans la paroisse de Ploemeur, dans celles de Guidel, de Lébin, de Locmaria, de Meslan, de Guele-Coumarho, les forêt de Botbleis et de Combout et tout ce qu'il avait dans le duché de Bretagne, en fief, arrière fief, en domaine, haute et basse juridiction, mais aussi ce qu'avait Amice dans la paroisse de Senonches, dans l'évêché de Chartres et tout cela contre une rente de 400 livres à prendre sur la terre de Sorel-le-Châtel et à Villers en Normandie ${ }^{107}$. Hervé de Léon avait donc été contraint de traiter devant

105. Le 28 février 1317, acte de l'échange de la terre de Châteaugiron, qui fut cédée par Brient de Châteaugiron au duc Jean III contre le manoir de " Demain " et ses dépendances. Ce titre est inséré dans les lettres de ratification du roi Philippe V le Long (Arch. dép. de Loire-Atlantique, E 161, n 25, original sur parchemin). En mars 1317, à Paris, Philippe V le Long ratifia l'échange entre Jean III, duc de Bretagne, et Brient, seigneur de Châteaugiron. Jean III aura le château et la baronnie de Châteaugiron; Brient de Châteaugiron aura les biens du duc dans le Léon, sauf les hommages de monsieur Hervé de Léon et de monsieur Bertrand du Chastel, les gros fiefs nobles, le château de Brest et les châteaux, villes, marchandes. Les estimations seront faites par Olivier Arel, Eon de Tréal et Georges Charlet (BnF, fonds français 8268, $\mathrm{f}^{\circ}$ 37-39, copie; Arch. nat., JJ 53, f $\mathrm{f}^{\circ} 36, \mathrm{n}^{\circ} \mathrm{79}$, copie; Registres du Trésor des Chartes, t. II : règnes des fils de Philippe le Bel. Première partie : règnes de Louis $X$ le Hutin et de Philippe V le Long, op. cit., n 366, p. 84-85; Dom MoricE, Pr., t. I, col. 1267-1267).

106. Boutaric, Edgar, Actes du Parlement de Paris, op. cit., t. II, 1299-1328, Paris, 1867, p. $423, \mathrm{n}^{\circ} 6678$, d'après Greffe, t. I, f ${ }^{\circ} 91$ v.

107. Cartulaires du Morbihan, op. cit., p. 425-426, ${ }^{\circ}$ 507; Médiathèque de Nantes, fonds Bizeul, n 1701, fr. 1545. 
les officiers du duc sans que les agents du roi soient intervenus alors qu'il était aussi question de droits et de fiefs dans l'évêché de Chartres relevant directement du roi de France (Cf. annexe 13 - La succession d'Henri IV de Léon).

C'est encore devant la cour ducale de Lesneven, en 1331, qu'Hervé de Léon, chevalier, sire de Noyon, régla une affaire concernant la succession de sa tante, Amice de Léon. Il s'accorda avec Olivier, fils de Guillaume de Léon, chevalier, sur le legs d'Amice. Celle-ci avait donné à Olivier le manoir de Caledan et 40 livres de rente mais Hervé de Léon s'y opposa car le manoir et les 300 livres de meubles devaient lui revenir en tant qu'aîné de son lignage. Hervé de Léon préféra dès lors payer 300 livres à son cousin ${ }^{108}$.

Six ans plus tard, en 1337, ce n'est toujours pas devant une cour royale qu'Hervé de Léon régla ses affaires de succession mais devant une autre cour ducale léonarde, celle de Saint-Renan, près de Brest. L'affaire concernait cette fois-ci rien moins que les droits de sa mère, Jeanne de Montmorency, sur la succession de son père. Hervé de Léon lui laissa en douaire 1200 livres de monnaie courante, 20 rais de froment de la mesure du domaine de Daoulas, 100 mines de froment et 100 autres mines d'avoine de la mesure de Buchi dans le duché de Normandie, avec la manoir de Rosene, dans l'évêché de Cornouaille, la forêt de Coetlenerc, la forêt de Plebanoez, l'hébergement nommé Bois Herot dans le duché de Normandie avec ses dépendances ${ }^{109}$. La succession du père d'Hervé de Léon continua à être réglée devant les autorités ducales. En 1338, devant la cour de Lesneven, Amice de Léon, sœur d'Hervé de Léon, le fils, obtint de son frère, 500 livres de rente et 2000 livres de monnaie courante en Normandie ou en France ${ }^{110}$. L'année suivante, devant la même cour, l'officier ducal attesta de l'accord entre Hervé de Léon, chevalier, seigneur de Noyon, et son frère Érard, sur les héritages de leurs père et mère dans les duchés de Bretagne et de Normandie, dans la terre de Picardie et en France. Érard gardait ce qu'il avait dans la baillie de Gaille-Fontaine selon la décision de leur père. Il devait avoir aussi la terre de Frémerville en Picardie avec les biens pouvant venir de l'héritage de Philippe, religieuse, sœur de leur mère, dans la même terre, avec la rente qu'avait leur père sur le seigneur de Longeval. Érard devait rendre à son frère toutes les lettres de retrait faites en son nom, spécialement les lettres d'appropriement sur la ville et la terre de Keralguezen alors à monsieur Maurice de Keralguezen, en la paroisse de Ploubennec, la ville de Kergangoaflan et son terroir dans la paroisse de Plougastel, évêché de Quimper ${ }^{111}$.

108. Dom MoRicE, Pr., t. I, col. 1356, d'après " pris sur l'original ».

109. BnF, ms. français 22325 , p. 820 , titres de Blain; Médiathèque de Nantes, fonds Bizeul, $n^{\circ}$ 1702, fr. 1546; Dom MoRICE, Pr., t. I, col. 1389-1391, pris sur " l'original à Blain ".

110. Médiathèque de Nantes, fonds Bizeul $1682, n^{\circ} 7$, parchemin, porte le sceau de cire brune de $2 \mathrm{~cm}$ de diamètre intact d'Even Charruel; Dom MoRICE, Pr., t. I, col. 1394, d'après " original à Blain ".

111. Médiathèque de Nantes, fonds Bizeul $1682, \mathrm{n}^{\circ} 9,28 \mathrm{~cm}$ x $22 \mathrm{~cm}$, parchemin; BnF, ms. français 22325, p. 844, Titres de Blain, copie; Dom MoRICE, Pr., t. I, col. 1396, « pris sur l'original à Blain ". 
Le duc Jean III put encore intervenir dans une seconde succession concernant l'énorme patrimoine des Avaugour (Cf. annexe 14 - La succession d'Henri III d'Avaugour).

Le $1^{\text {er }}$ février 1334 mourut Henri III d'Avaugour, seigneur de Goëlo, de Dinan-Sud, de Léhon, de Mayenne et de l'Aigle et depuis 1331 seigneur de La Roche-Derrien et de Châteaulin-sous-Trieux. Avec sa mort, s'éteignit la maison de Rennes car il n'avait eu que des filles de son mariage avec Jeanne d'Harcourt, qui vivait encore en $1346^{112}$. Ces trois filles furent :

- Jeanne, morte le 28 juillet 1327, qui avait épousé le frère cadet et utérin de Jean III, Guy de Bretagne, vicomte de Limoges, puis seigneur de Penthièvre, mort au manoir de Nigon-lès-Paris le 16 mars 1331. Jeanne n'eut de lui qu'une fille, Jeanne de Penthièvre qui était aussi en 1334 l'héritière incontestée du duc Jean III, duc de Bretagne et vicomte de Limoges.

- Marguerite, épouse d'Hervé VII de Léon, seigneur de Noyon-surAndelle.

- Isabeau, épouse alors de Geoffroy VIII, seigneur de Châteaubriant (qui mourut en 1347).

Le règlement de la succession d'Henri III ne fut guère aisé car les enjeux étaient non seulement financiers mais aussi hautement politiques. Il dura plusieurs décennies et commença en 1338, devant la cour du duc Jean III de Guingamp dont dépendait la terre de Goëlo. Marguerite d'Avaugour, dame de Noyon, fit estimer les biens de son père dans le Goëlo et le Guéméné. Elle demanda et obtint du sire de Quintin (cadet du lignage d'Avaugour), tuteur de Jeanne de Penthièvre, 300 livres de rente par an sur la terre de Mayenne et 500 livres sur les châtellenies de Châtelaudren et de Lanvollon. Jean III, qui avait été écarté de la gestion des biens de sa nièce par Henri III d'Avaugour, réussit à montrer sa supériorité puisqu'il est mentionné dans l'acte comme le souverain et le garde de sa nièce ${ }^{113}$. Pour le reste la succession fut réglée plus tard directement par Jeanne de Penthièvre, devenue alors duchesse de Bretagne, et par son époux, Charles de Blois. En 1348, elle abandonna à sa tante, Marguerite, la jouissance de l'hôtel parisien de son grand-père ${ }^{114}$. La mort de sa grand-mère maternelle, Jeanne d'Harcourt, veuve d'Henri III, entraîna un nouveau partage en 1354. Marguerite d'Avaugour reçut 1000 livres sur les terres de Normandie venant de Jean d'Harcourt. Isabeau, veuve du seigneur de Châteaubriant, obtint, le 8 avril de la même année, 500 livres de rente sur les châtellenies de Paimpol et le manoir de Correc, avec 1000 livres sur l'Echiquier de Rouen ${ }^{115}$. En août, Jeanne de Penthièvre ordonna de transférer la rente d'Isabeau assise sur

112. Voir Morvan, Frédéric, "La maison de Penthièvre (1212-1334), rivale des ducs de Bretagne ", dans MSHAB, t. LXXXI, 2003, p. 19-54.

113. L'acte est scellé pour Jeanne de Penthièvre par son grand-oncle, Guillaume d'Avaugour (Dom Morice, Pr., t. I, col. 1394-1395).

114. Publié par Jones, Michael, Recueil des actes de Charles de Blois et de Jeanne de Penthièvre, duc et duchesse de Bretagne (1341-1364), suivi des actes de Jeanne de Penthièvre (1364-1384), Rennes, 1996, p. 115, n 109.

115. Arch. dép. de Loire-Atlantique, E $176, n^{\circ} 5$ et 7 . 
les recettes de Guingamp, de Châtelaudren, de Paimpol et de Lanvollon, sur celle de Nantes. L'affaire n'est toujours pas réglée en 1376, puisque Jeanne de Penthièvre, ne pouvant pas payer sa tante, lui donna la terre, le château et la châtellenie de L'Aigle en Normandie, avec la terre de Rémalard dans le comté du Perche, valant les deux tiers des 500 livres dues ${ }^{116}$.

Ainsi, à sa mort, Jean III avait donc réussi à intervenir dans les plus importantes successions nobiliaires, mais il devait agir avec la plus grande prudence car nombre de ses vassaux étaient devenus de grands seigneurs du royaume de France, des vassaux et des proches conseillers du roi de France, comme Henri III d'Avaugour. Dès qu'apparaissait un conflit de succession les concernant, la main royale les protégeait. Il est manifeste qu'à partir du moment où Jean III, grâce à sa proche parenté avec les Valois, entra en grâce auprès des rois de France, il fallut reconnaître son autorité et ses droits, suivre les procédures et se soumettre à ses cours de justice.

Pour terminer, il est nécessaire de remarquer l'évolution dans l'adéquation entre les règlements des conflits de succession nobiliaire et le gouvernement du duché de Bretagne. Ce phénomène est parfaitement logique lorsqu'il s'agit de la dévolution des fiefs les plus importants du duché, lorsque cela concernait les plus grandes familles de la noblesse bretonne, souvent proches parentes des ducs de Bretagne, des rois d'Angleterre et de France. Ces successions étaient un moyen efficace des gouvernants afin d'accroître leur autorité, surtout lorsqu'elles s'avéraient importantes politiquement et financièrement, lorsqu'elles étaient difficiles, lorsque le lignage n'avait plus d'héritiers mâles et principalement lorsque le patrimoine familial était à diviser entre plusieurs héritières. Le roi de France, Philippe Auguste, contraignit ainsi la noblesse bretonne à choisir son camp et à procéder à des partages par anticipation et dans l'urgence. Son protégé, Pierre de Dreux, duc de Bretagne, réussit, grâce à quelques successions, à accroître son pouvoir. Mal lui en prit puisque, dès qu'il se trouva en difficulté, une grande partie de la noblesse du duché se souleva contre lui et lui arracha, avec l'appui du roi de France à qui elle s'était ralliée, des privilèges successoraux non négligeables. Le fils de Pierre, le duc Jean I ${ }^{\text {er }}$ et surtout le fils de ce dernier, Jean II, dont les légitimités ne pouvaient plus être remises en cause, parvinrent, en réglant quelques successions, à renforcer leur autorité, mais aussi à augmenter leur puissance territoriale aux dépens surtout des Lanvaux et des vicomtes de Léon. Jean I ${ }^{\text {er }}$ utilisa davantage la force. Jean II s'appuya sur le droit. Tous deux parvinrent à mettre en place les bases d'une principauté autonome et puissante.

Le désastre de Courtrai, en 1302, remit tout en question. Les rois de France, Philippe Le Bel et son fils Philippe le Long, utilisèrent tous les moyens juridiques afin d'imposer leur autorité en Bretagne. Les règlements des successions nobiliaires, surtout celui des comtes de La Marche

116. Arch. dép. de Loire-Atlantique, E 218, $\mathrm{n}^{\circ} 16$; JonEs, Michael, Recueil des actes de Charles de Blois et de Jeanne de Penthièvre, ${ }^{\circ} 339$. 
et d'Angoulême, seigneurs de Fougères et de Porhoët, furent leurs principaux atouts. Toutefois, le duc Jean III sauvegarda son autorité, très certainement grâce à ses liens privilégiés avec les Valois, mais il dut se montrer prudent et discret. Le temps n'était plus à profiter des successions nobiliaires afin de s'emparer de tel ou tel château ou de telle ou telle terre. La haute noblesse bretonne disposait de domaines très importants dans tout le nord du royaume de France. Nombre de ses membres étaient des vassaux directs du roi de France et celui-ci aurait pu ne pas apprécier de voir un des plus grands vassaux de son royaume toucher aux biens de seigneurs moyens sur lesquels le plus souvent il reposait.

La mort de Jean III, en 1341, amena un conflit de succession entre Jeanne de Penthièvre et son oncle, Jean de Montfort, demi-frère du duc, que seul le roi de France pouvait régler. Il tenta de le faire en se référant aux successions de la noblesse bretonne comme si le duché de Bretagne avait été un fief qui aurait appartenu à une grande famille noble. Jean de Montfort ne l'accepta pas et considéra la Bretagne comme une principauté régie par des règles de succession différentes de celles de la noblesse. Par son refus, il déclencha la guerre de succession de Bretagne et plongea alors la péninsule armoricaine dans le chaos.

Annexe 1 - La succession d'Harcoul de Subligny

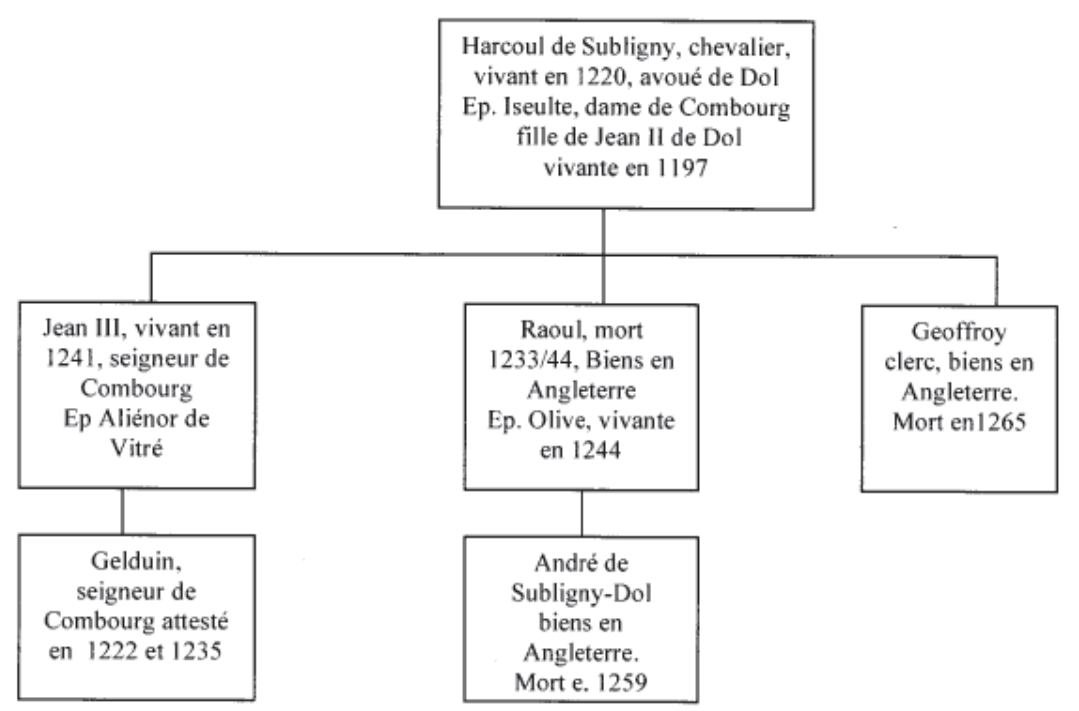


Frédéric MoRvan

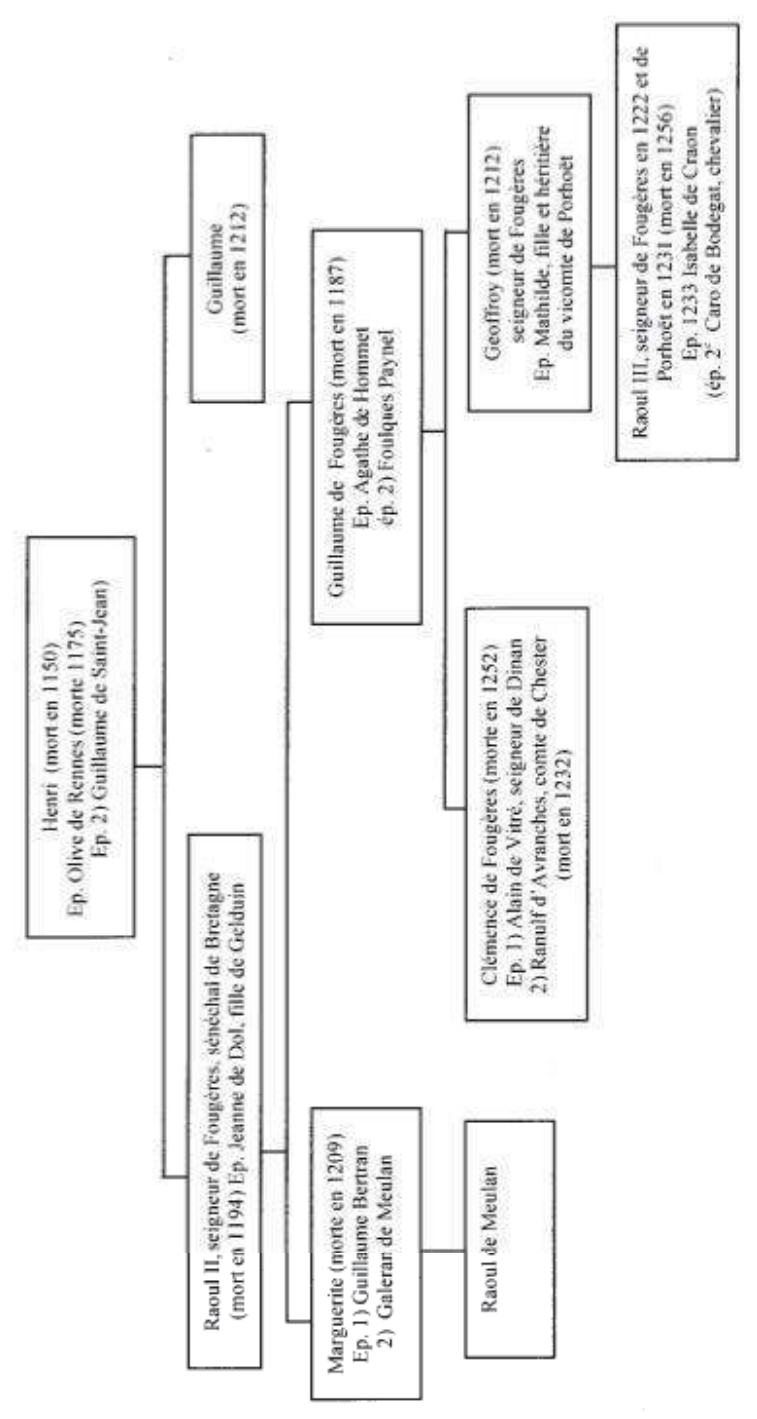

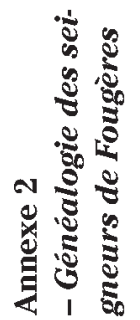

40 
Les règlements des conflits de succcession dans la noblesse bretonne

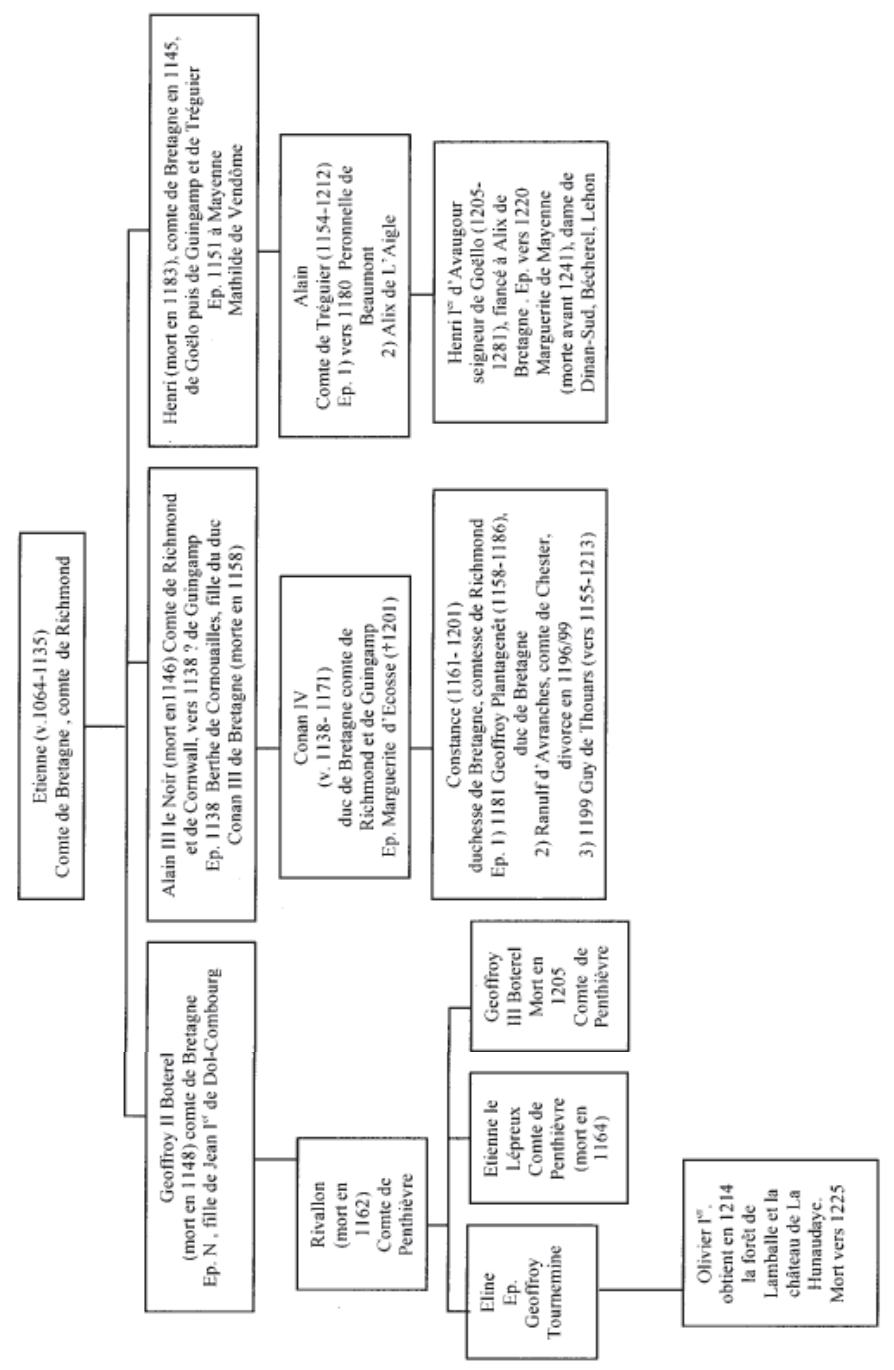


Frédéric MoRvaN
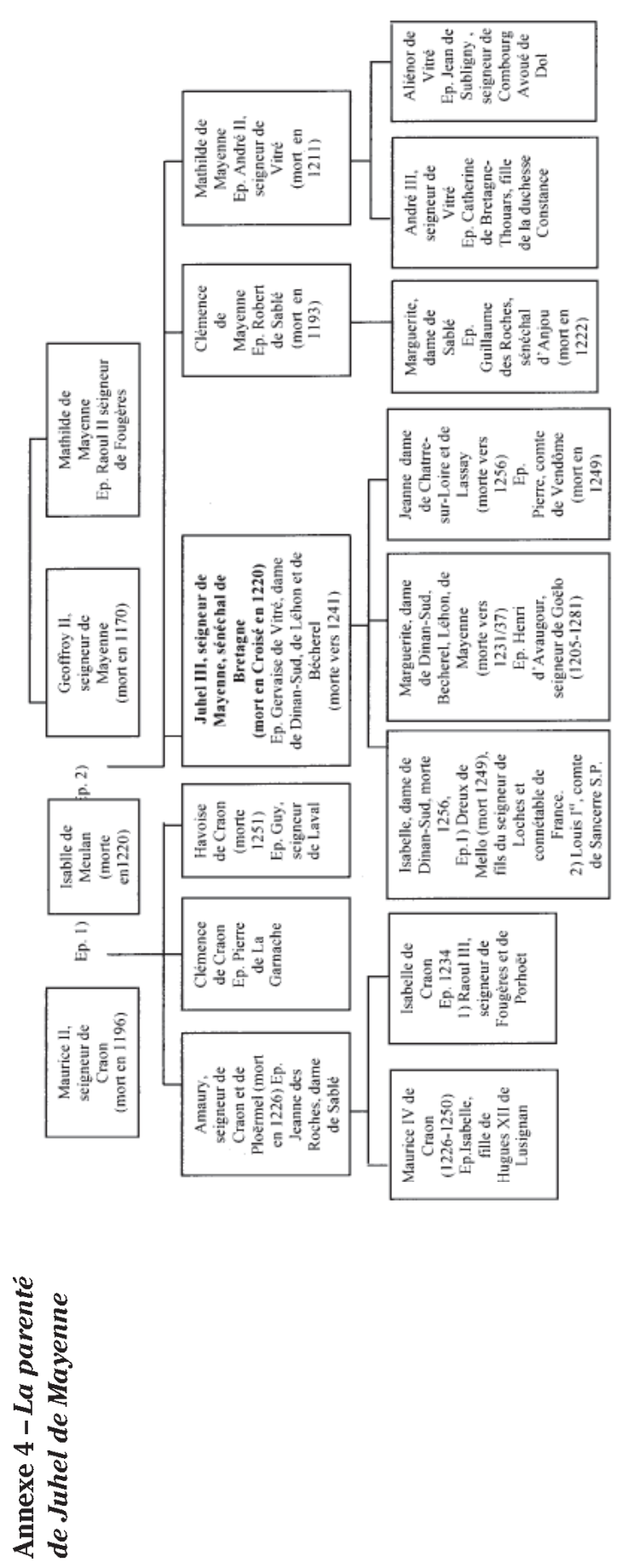
Les règlements des conflits de succcession dans la noblesse bretonne
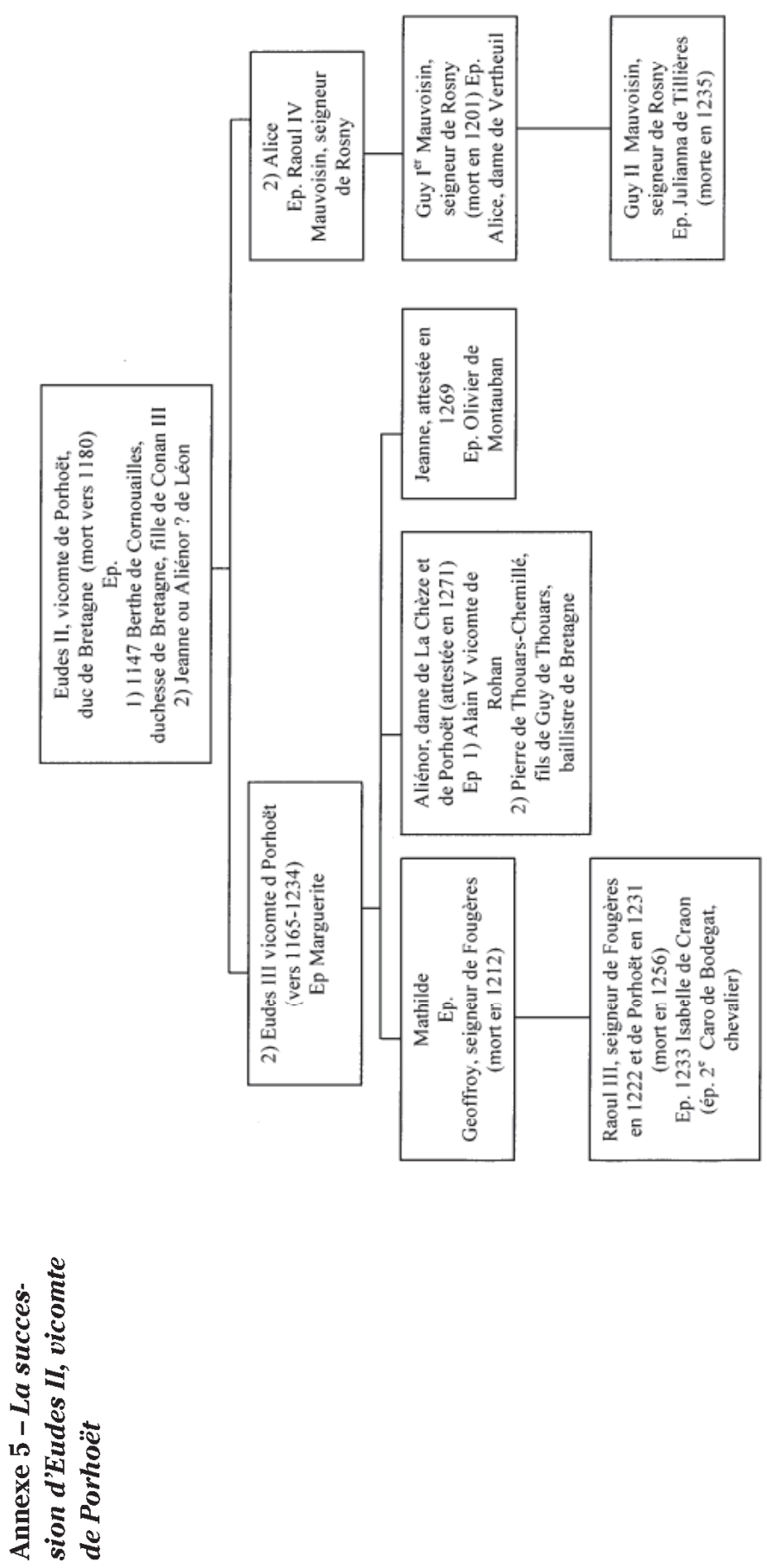
Frédéric MORvan
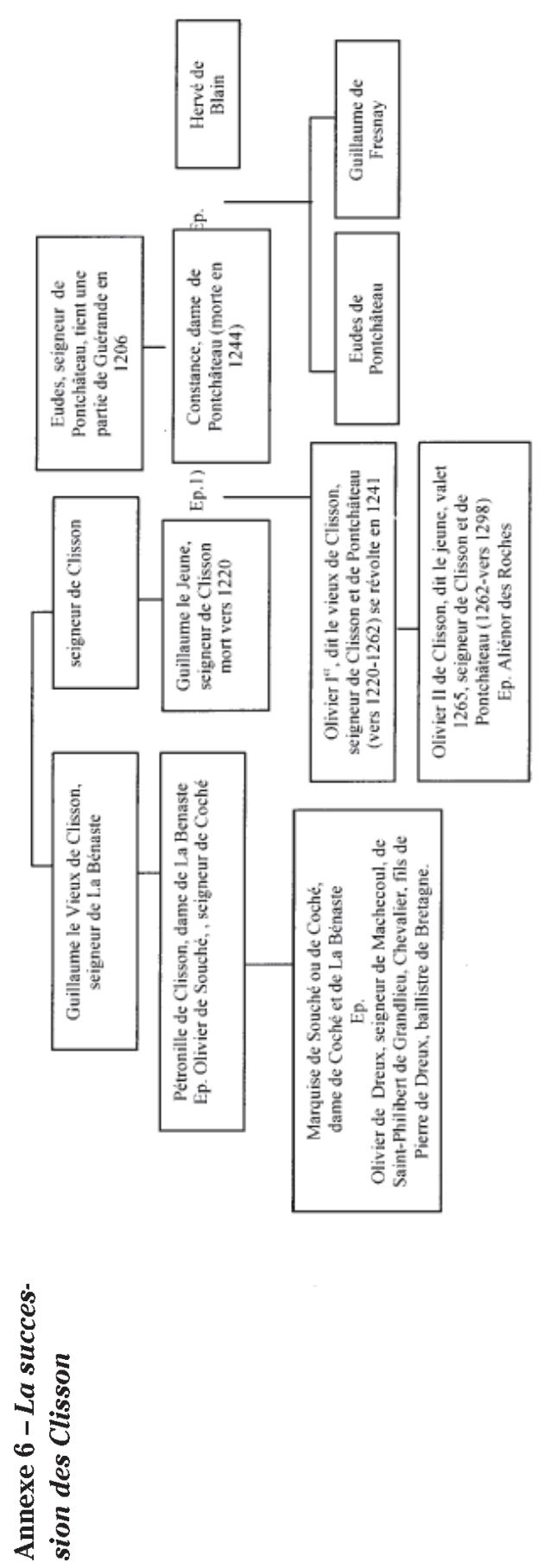
Les règlements des conflits de succcession dans la noblesse bretonne
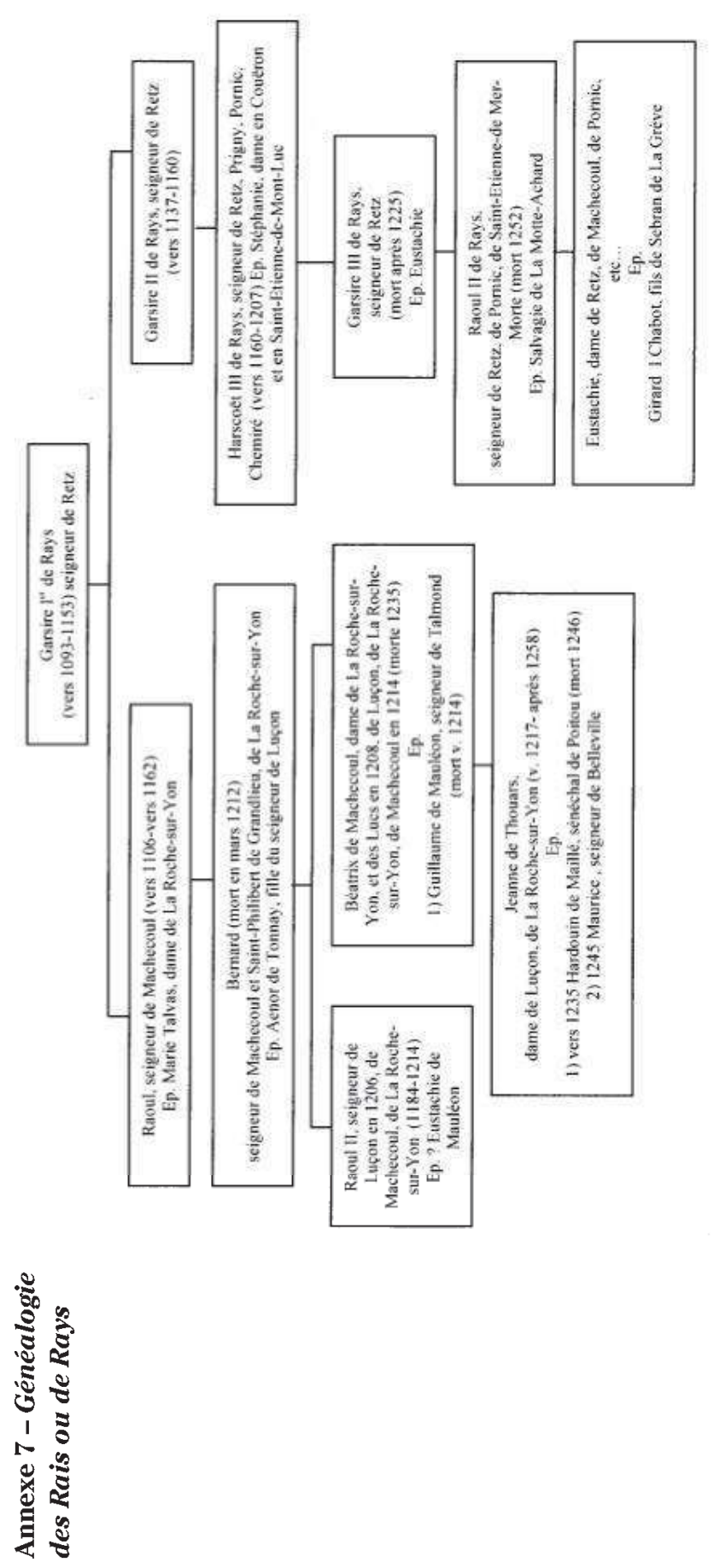
Frédéric MORVAN

\section{Annexe 8 - La succession d'Henri I' d'Avaugour}

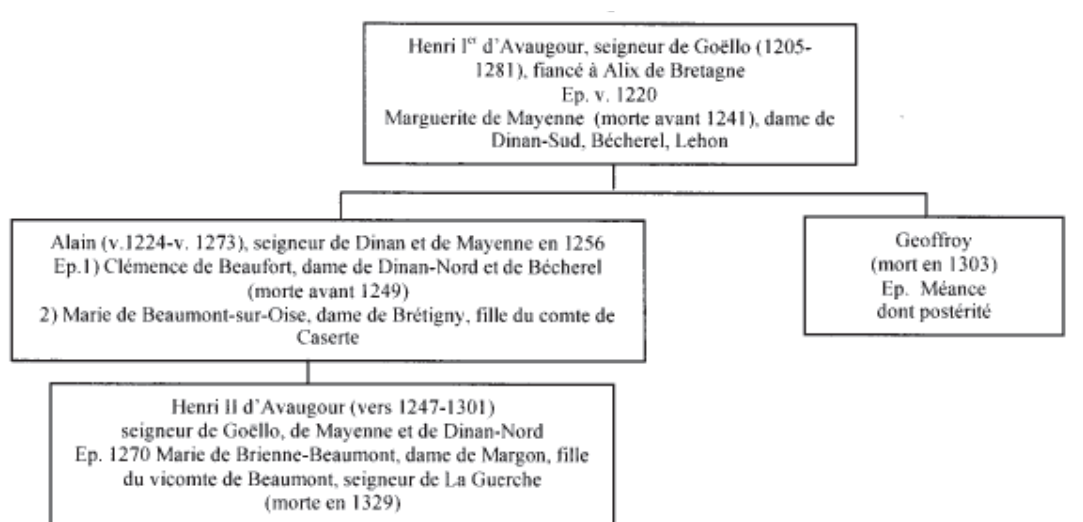

Annexe 9-La succession des Montfort

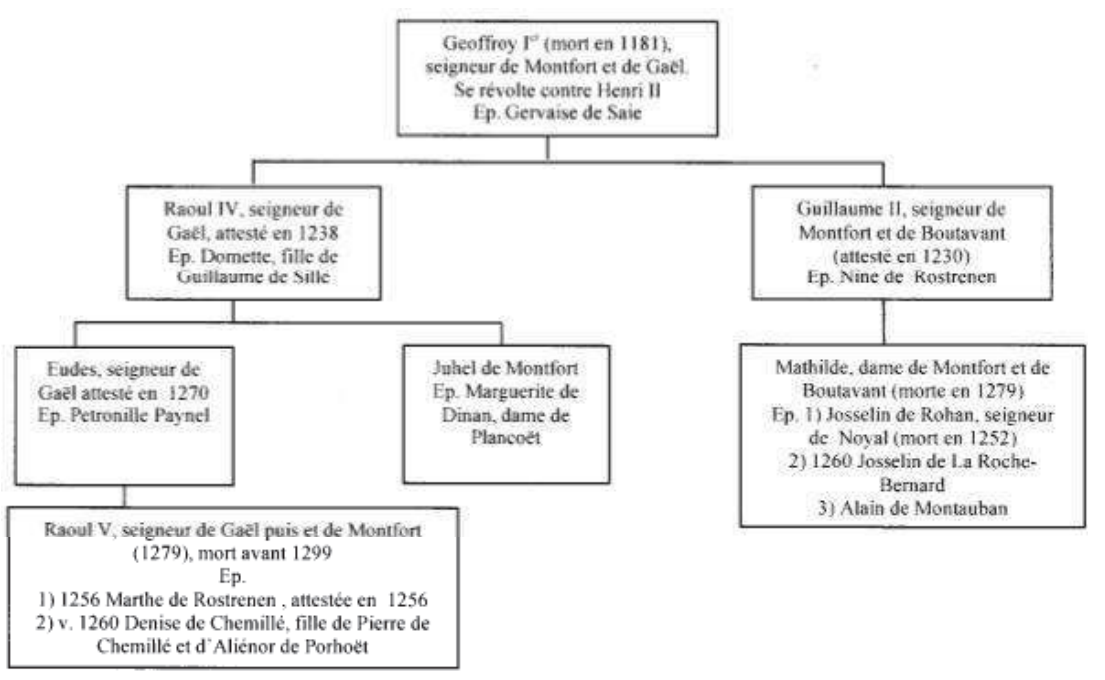


Les règlements des conflits de succcession dans la noblesse bretonne

Annexe 10 - La succession d'Hervé III, vicomte de Léon

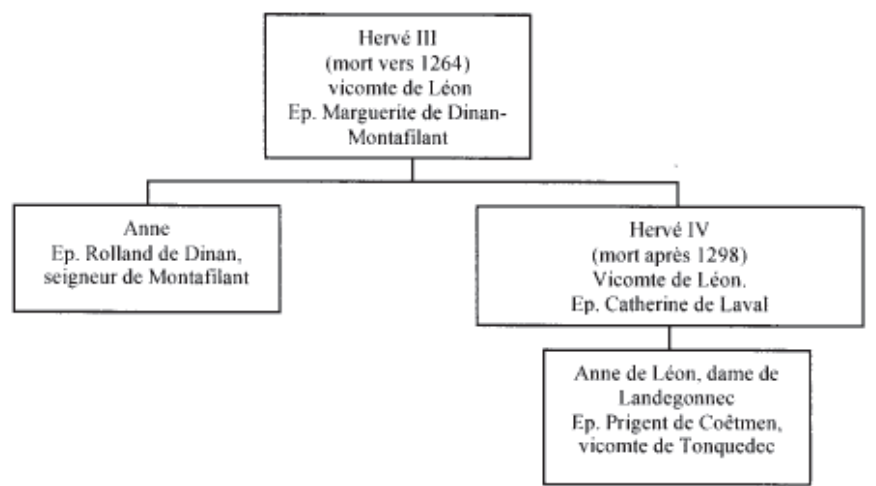

Annexe 11 - La succession d'Alain VI, vicomte de Rohan

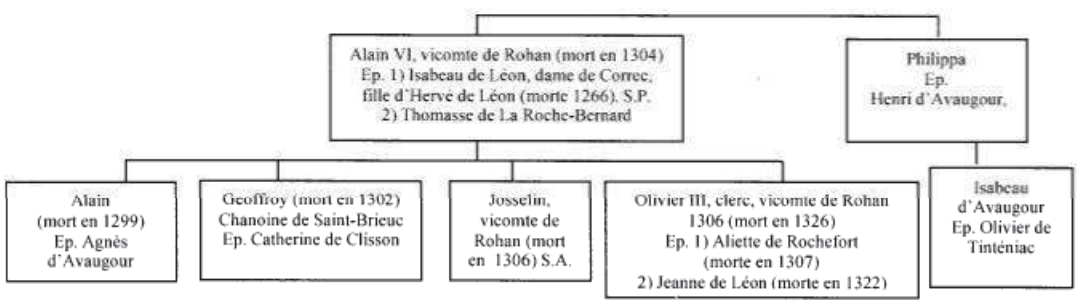


Frédéric MoRvan
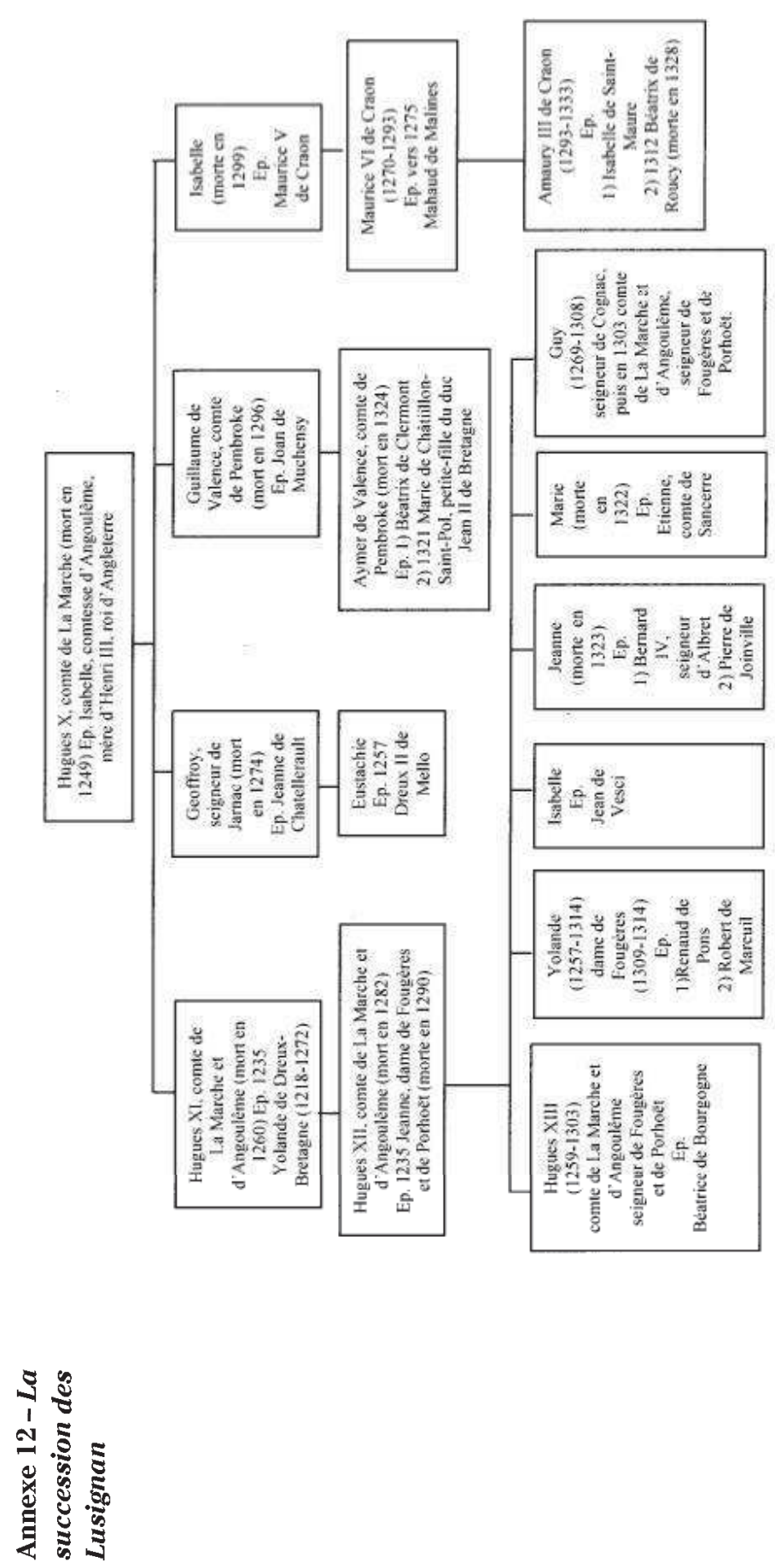
Les règlements des conflits de succcession dans la noblesse bretonne

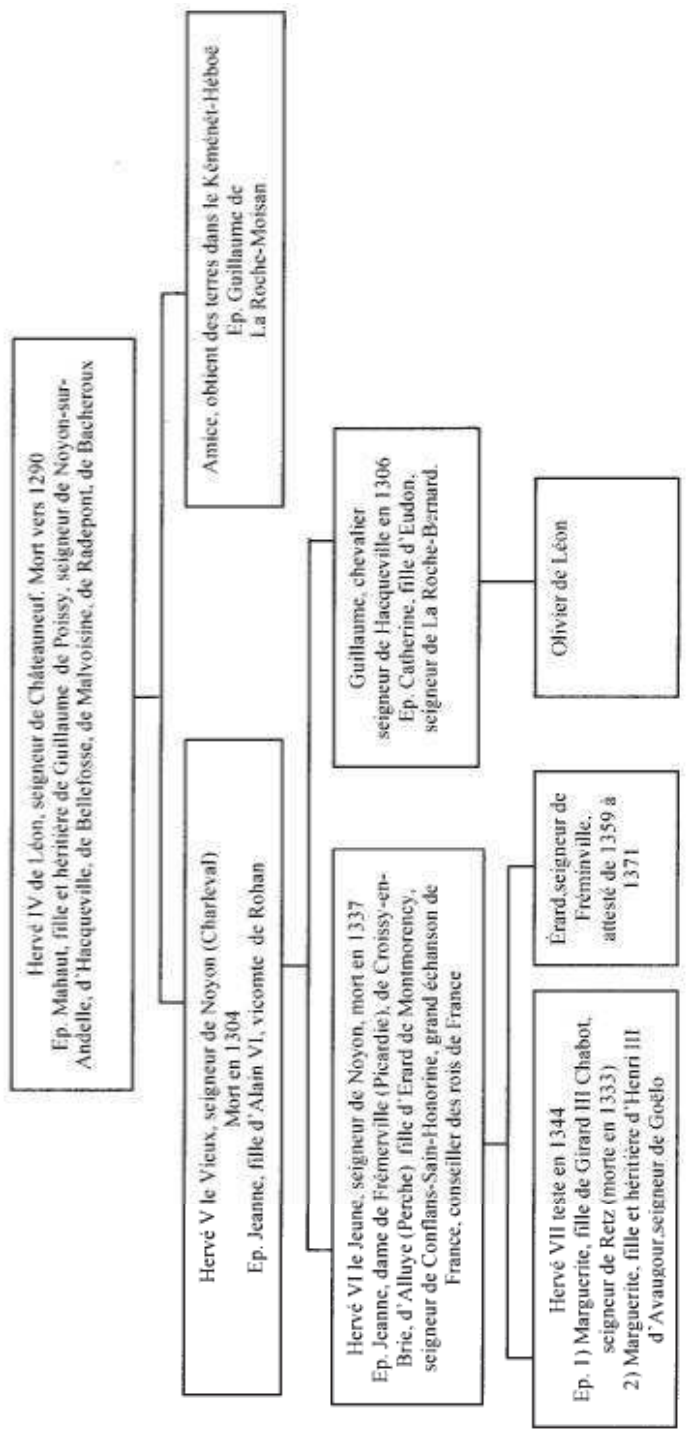

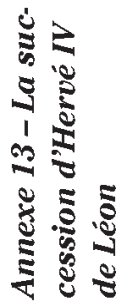


Frédéric MORVAN

Annexe 14 - La succession d'Henri III d'Avaugour

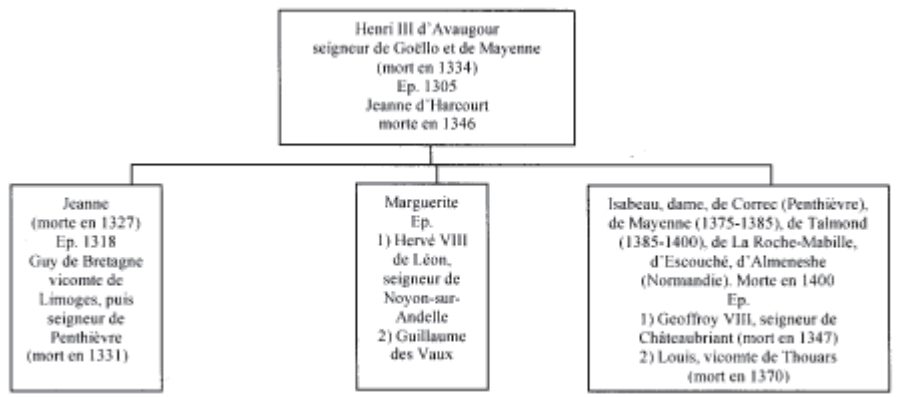

Annexe 15 - Généalogique de la maison ducale de Bretagne

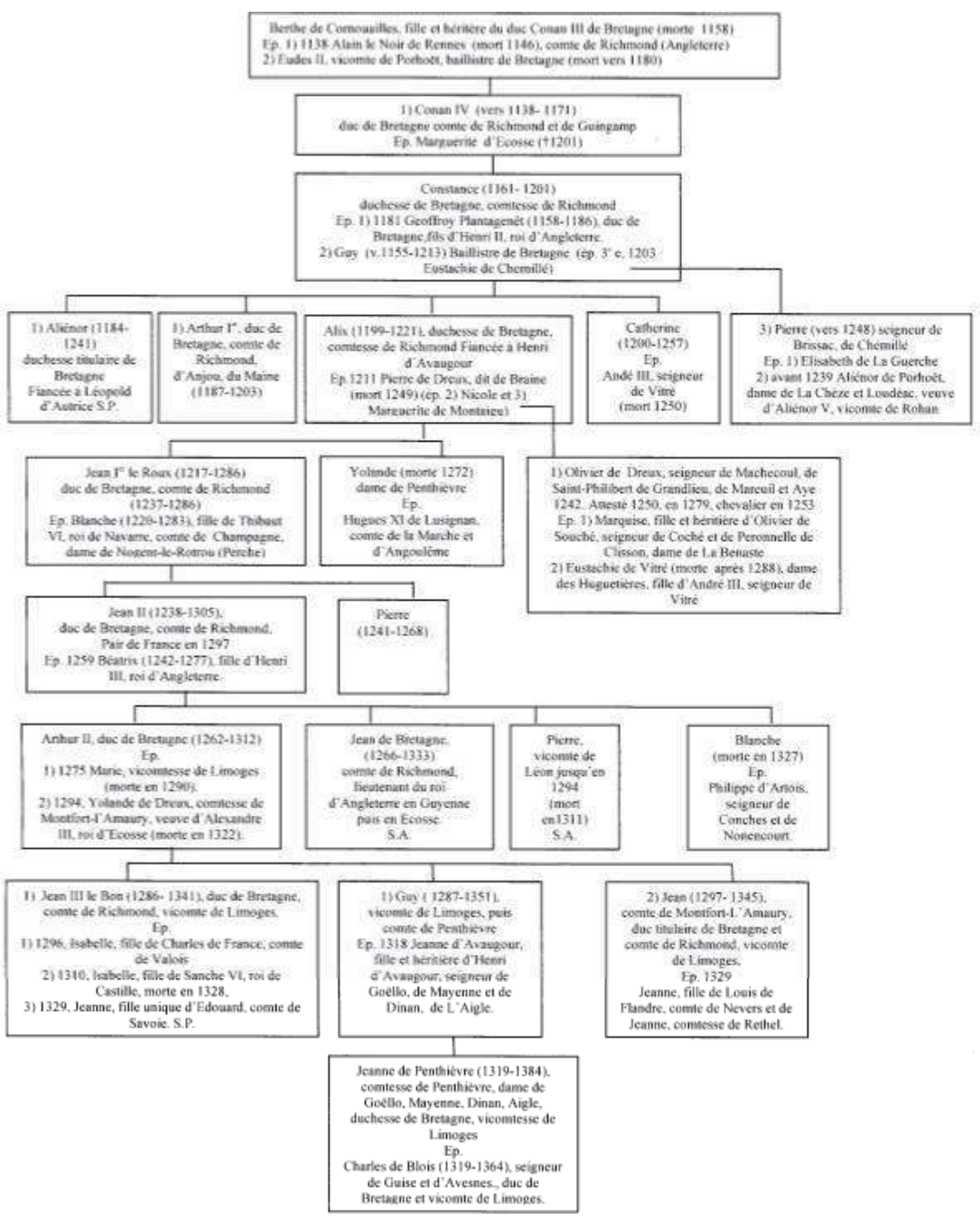

50 
Annexe 16 - Généalogie des Eudonides

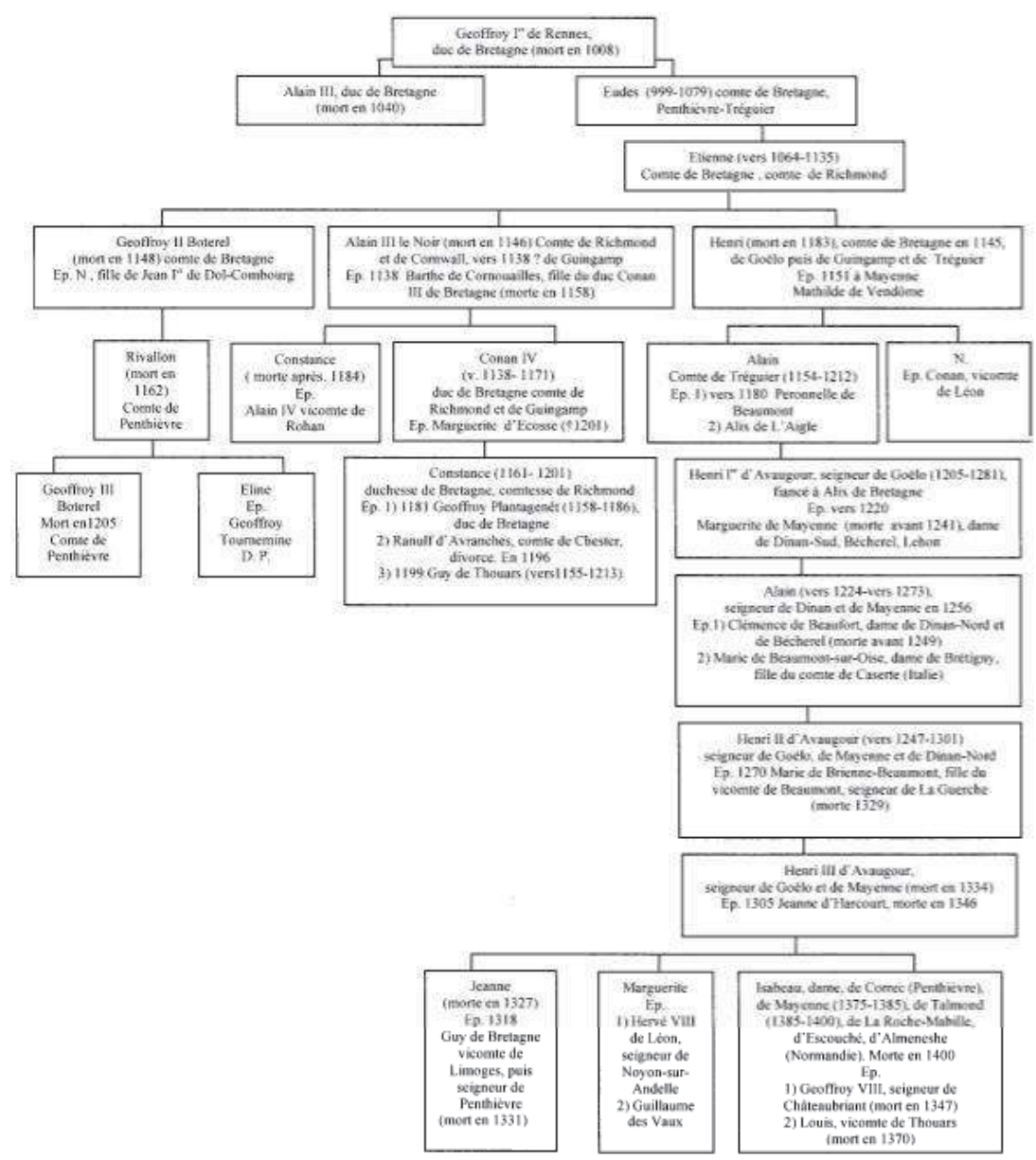


Frédéric MoRvan

\section{Annexe 17 - Généalogie des Porhoët}

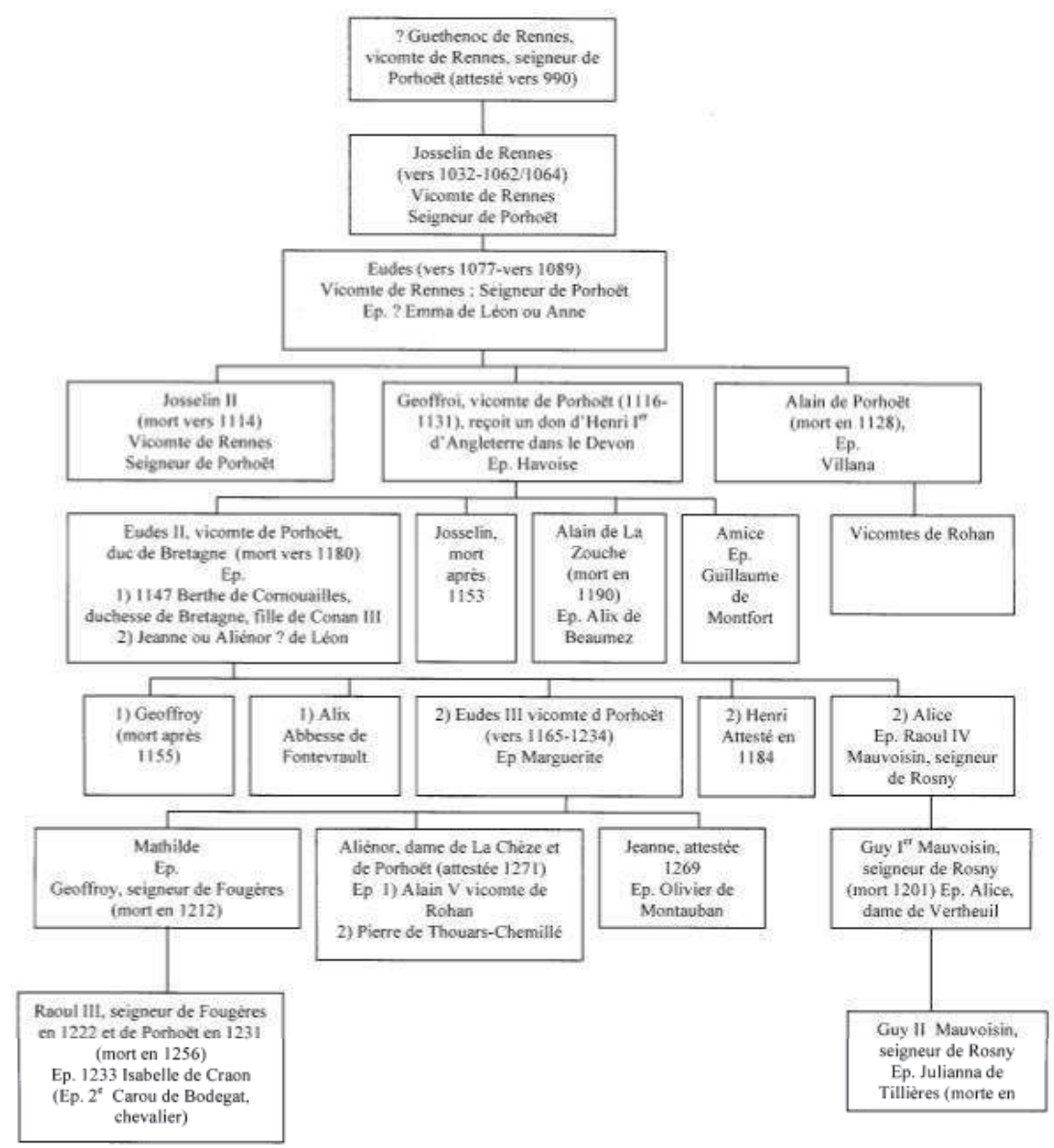



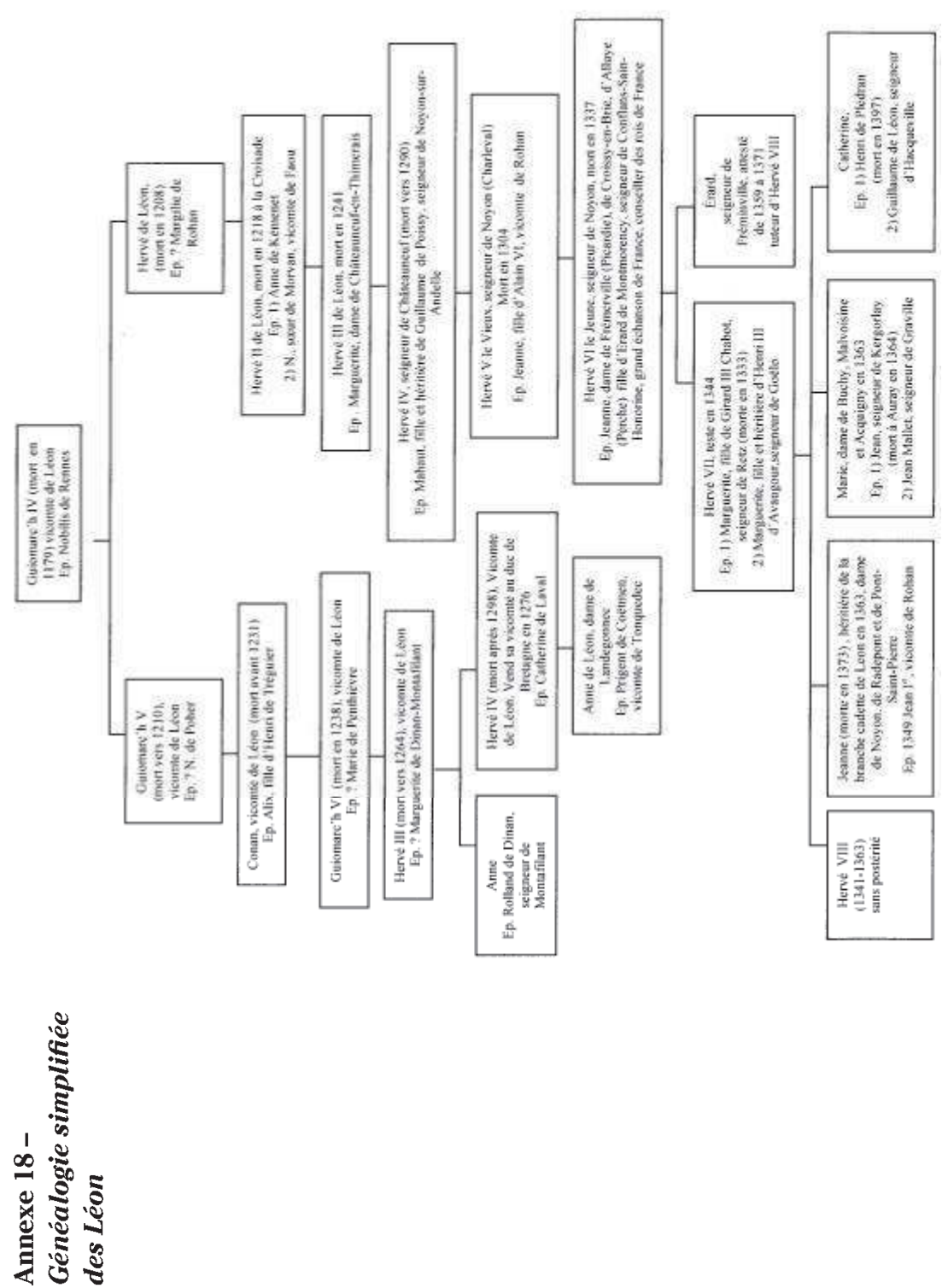


\section{RÉSUMÉ}

L'histoire médiévale bretonne est marquée par les conflits de succession dans la noblesse bretonne, si importants qu'ils ont nécessité l'intervention des autorités princières. En s'inspirant des méthodes de Geoffroy Plantagenêt, duc de Bretagne de la fin du $\mathrm{XII}^{\mathrm{e}}$ siècle et surtout de celles de Philippe Auguste, roi de France, qui obtint dès 1205 le ralliement de la noblesse bretonne contre des avantages lors de certaines successions, les nouveaux ducs de Bretagne de la branche capétienne de Dreux profitèrent des conflits entre héritiers pour non seulement s'imposer, mais aussi renforcer leur autorité.

Pierre I $^{\text {r }}$ (1214-1237) profita ainsi des décès du Geoffoy de Penthiève et de Juhel de Mayenne afin de contrôler le nord de son duché. Son fils, Jean $\mathbf{I}^{\text {er }}$ (1237-1286), intervint si bien dans les conflits entre les héritiers des riches fiefs de Porhoët, de Pontchâteau et de Dinan, qu'il devint le maître incontesté du duché. Son fils, Jean II n'avait plus qu'à administrer le duché en réglant les quelques conflits de succession qui se présentaient à lui. Le désastre de la bataille de Courtrai en $\mathbf{1 3 0 2}$ et le rôle ambigu des grands feudataires du royaume (dont le duc de Bretagne) lors des guerres de Flandres amenèrent les rois de France à intervenir dans le duché. Profitant de la mort en 1308 de Guy de Lusignan, Philippe le Bel s'empara de ses terres, dont les deux fiefs les plus importants de Bretagne, Fougères et le Porhoët. Philippe V n'autorisa pas le duc Jean III à annexer à son Domaine la terre de Châteaugiron aux dépens des héritiers de ce fief. Grâce à ses relations familiales avec les rois Charles IV et surtout Philippe VI de Valois, ce duc obtint tout de même le droit de régler lui-même les successions nobiliaires de son duché, mais en respectant les intérêts des héritiers, surtout lorsqu'ils détenaient, comme les Léon ou les Avaugour, d'importants fiefs dans le royaume de France.

\section{ABSTRACT}

The Breton medieval history was marked by such important succession disputes among the Breton aristocracy that they required the intervention of the prince's administration. Drawing their inspiration from Geoffroy Plantagenêt, who was the duke of Brittany at the end of the $12^{\text {th }}$ century, and above all from Philippe Auguste, king of France, who, in return for favours concerning some successions, managed to win over the Breton aristocracy, the new dukes of Brittany of the Dreux Capetian branch took advantage of the disputes between the heirs not only to establish but also to reinforce their power.

Pierre $1^{\text {er }}$ (1214-1237) took advantage of the deaths of Geoffroy de Penthièvre and Juhel de Mayenne to control the north of his duchy. His son Jean I (1237-1286) played so clever a part in the resolution of the dispute between the heirs of the rich fiefs of Porhoët, Pontchâteau and Dinan that he managed to become the undisputed master of Brittany. Then, his son Jean II only had to govern the duchy and settle the few succession disputes that occurred during the period under his rule. The disaster at Courtrai in 1302, as well as the ambiguous role that was played by some of the kingdom's prominent lords - among whom the duke of Brittany must be numbered - in the Flandres wars, caused the kings of France to intervene in Brittany. Taking advantage of the death of Guy de Lusignan in 1308, Philippe le Bel seized his lands and, by doing so, took control of two of the most important fiefs in Brittany: Fougères and Porhoët. Philippe v didn't grant Duke Jean iii permission to incorporate - at the expense of its heirs - the land of Châteaugiron into his own property. However, thanks to his kinship with kings Charles iv and particularly Philippe VI de Valois, Jean III managed to obtain the right to settle the nobiliary successions in his duchy, provided he respected the heirs' interests, especially when those latter-namely the Léons and the Avaugours - held important fiefs in the kingdom of France. 